\title{
Antitumor Activity of Artemisinin and Its Derivatives: From a Well-Known Antimalarial Agent to a Potential Anticancer Drug
}

\author{
Maria P. Crespo-Ortiz ${ }^{1}$ and Ming Q. Wei ${ }^{2}$ \\ ${ }^{1}$ Department of Biomedical Science, Faculty of Basic and Health Science, Santiago de Cali University, Pampalinda Campus, \\ Cali, Colombia \\ ${ }^{2}$ Division of Molecular and Gene Therapies, Griffith Health Institute and School of Medical Science, Griffith University, \\ Gold Coast Campus, Southport, QLD 4222, Australia
}

Correspondence should be addressed to Maria P. Crespo-Ortiz, mdpcrespo@gmail.com

Received 1 August 2011; Accepted 29 August 2011

Academic Editor: Masa-Aki Shibata

Copyright () 2012 M. P. Crespo-Ortiz and M. Q. Wei. This is an open access article distributed under the Creative Commons Attribution License, which permits unrestricted use, distribution, and reproduction in any medium, provided the original work is properly cited.

Improvement of quality of life and survival of cancer patients will be greatly enhanced by the development of highly effective drugs to selectively kill malignant cells. Artemisinin and its analogs are naturally occurring antimalarials which have shown potent anticancer activity. In primary cancer cultures and cell lines, their antitumor actions were by inhibiting cancer proliferation, metastasis, and angiogenesis. In xenograft models, exposure to artemisinins substantially reduces tumor volume and progression. However, the rationale for the use of artemisinins in anticancer therapy must be addressed by a greater understanding of the underlying mechanisms involved in their cytotoxic effects. The primary targets for artemisinin and the chemical base for its preferential effects on heterologous tumor cells need yet to be elucidated. The aim of this paper is to provide an overview of the recent advances and new development of this class of drugs as potential anticancer agents.

\section{Introduction}

Cancer remains as a life-threatening disease and a leading cause of death as its control has been difficult. Although, a range of conventional therapies based on chemotherapy, surgery, and radiotherapy are available, these approaches are in many cases of limited efficacy [1]. Moreover, current anticancer regimens are frequently associated with significant levels of toxicity and the emergence of drug resistance. One major challenge to relieve cancer burden is to develop highly effective drugs with specificity on cancers but little or no side effects on normal mammalian cells.

Many research projects have been focused on developing new chemotherapies either by exploring the anticancer ability of novel compounds or by assessing drugs conventionally used in other clinical diseases. Natural products have been found to be a relevant source of novel and potent bioactive compounds with minimal side effects in vivo. Plant derivatives have been known to be effective against a range of di- seases with broad antimicrobial activity, and some have also exhibited significant antitumor activity. One of the promising compounds is artemisinin, a naturally occurring antimalarial with anticancer properties [2]. Artemisinin and its derivatives, which are commonly used in malaria therapy, have also potent anticancer activity in the nano- to-micromolar range in sensitive and drug- or radiation-resistant cell lines [3-5]. Importantly, artemisinin is one of the very few drugs that have been widely used as antimalarials but has no significant side effects [6] or clinical resistance, although tolerance has been reported [7]. Recently, growing amount of research has focused on the mechanisms underlying the action and response to artemisinin-like drugs.

In this review, we will revisit some of the key issues in the development of artemisinin and its analogs as anticancer agents to better understand the mechanisms of their antitumor effects from the insights of new gained knowledge. By considering the benefits, limitations, and current and future development of artemisinins, we can then identify emerging 
questions and address future research needs in this promising field of cancer drug discovery.

\section{Artemisinin and Its Derivatives}

Artemisinin is a sesquiterpene lactone with a 1,2,4-tiroxane ring system (Figure 1). This endoperoxide compound is extracted from the Chinese herb qinghaosu (Artemisia annua or annual wormwood) which was used for treating fevers for over two millennia [8]. Despite its efficacy, the prototype drug, artemisinin, has pharmacokinetic limitations. Naturally, artemisinin has low solubility in water or oil, poor bioavailability, and a short half-life in vivo $(\sim 2.5 \mathrm{~h})[9,10]$. To overcome some of these problems, three generations of artemisinin-like endoperoxides including semisynthetic derivatives and fully synthetic compounds have been developed. So far, two generations of semisynthetic derivatives of artemisinin such as artesunate, arteeter, artemether, and artemisone have been effectively used as antimalarials with good clinical efficacy and tolerability (Figure 1).

Semisynthetic artemisinins are obtained from dihydroartemisinin (DHA), the main active metabolite of artemisinin $[11,12]$. The first generation of semisynthetic artemisinins includes arteeter and artemether, the lipophilic artemisinins, whereas artesunate is the water soluble derivative $[11,12]$. Artemisone, a second-generation artemisinin, has shown improved pharmacokinetic properties including longer half-life and lower toxicity [13]. So far, artesunate is the derivative that is commonly used in the antimalarial combination therapy.

Fully synthetic artemisinin derivatives have also been designed by preserving the peroxide moiety which confers potent drug activity. These compounds are easily synthesized from simple starting materials, thus being currently under intense development [14-17].

\section{Antitumor Mechanism of Action of Artemisinin}

In the malaria parasite, the endoperoxide moiety of artemisinin has been shown to be pharmacologically important and responsible of the antimalarial activity $[18,19]$. The endoperoxide bond is thought to be activated by reduced heme (FPFeII) or ferrous iron (FeII) [20], leading to cytotoxic carbon-centered radicals which are highly potent alkylating agents [21]. Radicals may target essential parasite macromolecules causing parasite's death. However, the precise mechanism of action and primary target of artemisinin remain under study. In Plasmodium, it has been postulated that artemisinin may target organelles such as the mitochondrion, endoplasmic reticulum, and the digestive vacuole (reviewed in [22]). Some postulated molecular targets include heme alkylation, protein alkylation, $\mathrm{Ca}^{2+}$ ATPase (SERCA) inhibition, membrane damage, and loss of mitochondrial potential (reviewed in [22]). Despite the continuous debate on artemisinin activation and specific targets, supporting evidence points that heme or ferrous iron is required for potent activity [23]. This observation has been substantiated in other systems. In Schistosomas, artemether has an exquisite action against the tegument; this activity is also enhanced by iron [24].

Interestingly, the potent anticancer action of artemisinin can also be attributed to the endoperoxide bond (red square in Figure 2) and shares the same parasitical chemical base. Lack of the endoperoxide moiety does not completely abrogate anticancer activity [25] but significantly reduces cytotoxicity to only fiftieth compared to those compounds with the trioxane ring [26-28]. Residual anticancer activity may be associated with an alternative peroxide-independent mechanism [26]. In a general consensus, iron and heme or heme-bound proteins have been involved in the bioreductive activation of artemisinin [29-31]. In most of the systems, preloading of cancer cells with iron or iron-saturated holotransferrin (diferric transferrin) triggers artemisinin cytotoxicity [32-35] with an increase in artemisinin activity up to 100 -fold in some cell lines [36]. Moreover, artemisinins tagged to iron-carrying compounds exhibit greater activity compared with that of artemisinin alone [37-39]. Recently, it was shown that chemical modulation using succinylacetone, a heme synthesis inhibitor, decreases DHA cytotoxicity in HL-60 (human promyelocytic leukemia cells) [35]. This was consistent with previous studies showing that induction of heme oxidase followed by downregulation of the heme synthesis genes may also inhibit cytotoxicity of novel artemisinin dimers in the same cancer line [40]. Similarly, treatment with desferroxamine (DFO), an iron chelator, renders compounds inactive [41]. Iron and heme metabolism may have a relevant role in the selective antitumor activity of artemisinin. Continued proliferation and growth of malignant cells require higher iron metabolism to achieve processes of cell survival [35]. Therefore, cancer cells exhibit an increase in transferrin receptors (TfR) which are responsible for the iron uptake and regulation of intracellular concentrations. Levels of expression of TfR in cancer cells may vary depending on the cell line. However, they differ substantially from normal cells leading to a high selectivity index of artemisinin and its derivatives. Efferth et al. reported that leukemia (CCRFCEM) and astrocytoma (U373) cells express TfR in 95\% and $43 \%$ of the cell population, whereas normal monocytes only account for approximately $1 \%[42,43]$. Blocking the TfR by pretreatment with specific monoclonal antibodies abrogates artemisinin activity [43].

It has been hypothesized that iron-activated artemisinin induces damage by release of highly alkylating carbon-centered radicals and radical oxygen species (ROS) (Figure 2) $[28,35]$. Radicals may play a role in the cell alterations reported in artemisinin-treated cancer cells such as enhanced apoptosis, arrest of growth, inhibition of angiogenesis, and DNA damage (Figure 2). Several studies have also associated artemisinin toxicity with impaired cytokinesis, enhanced levels of oxidative stress, inhibition of tumor invasion, migration, and metastasis (reviewed in [44]). ROS generation may contribute with the selective action of artemisinin on cancer cells. Tumor cells have enhanced vulnerability to ROS damage as they exhibit lower expression of antioxidant enzymes such as superoxide dismutase, catalase, and gluthatione peroxidase compared to that of normal cells $[45,46]$. Hence, increasing oxidative stress is a common anticancer 


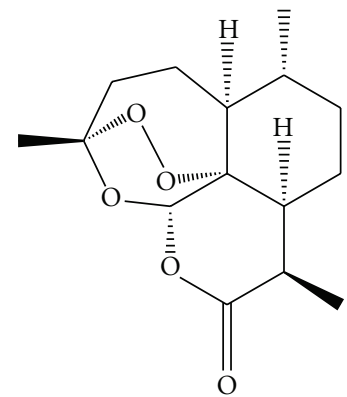

(1)

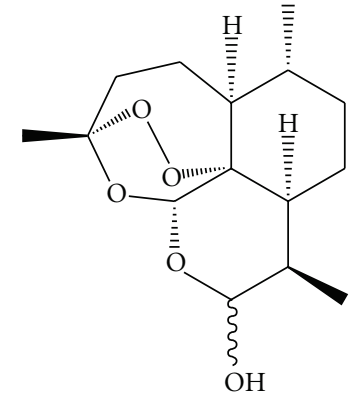

(2)

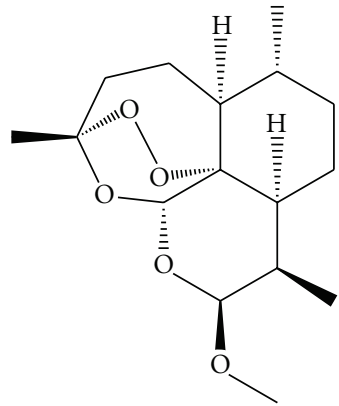

(3)

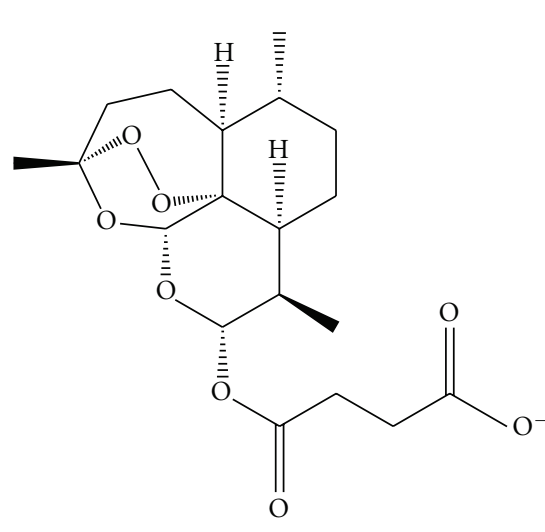

(4)

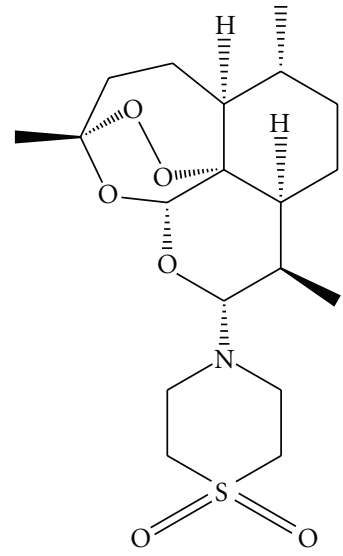

(5)

FIGURE 1: Chemical structure of artemisinin antimalarials (artemisinins) with anticancer activity. Artemisinin (1), dihydroartemisinin (DHA) (2), artemether (3), artesunate (4), and artemisone (5).

mechanism of antitumor agents [47]. In addition, the selectivity of artemisinin may be boosted by preferential targeting of cancer biomarkers or overexpressed cancer genes and proteins which are not detectable in normal differentiated tissues [48].

\subsection{Generation of ROS as a Primary Effector of Cytotoxicity.} As in Plasmodium, the artemisinin molecular targets in cancer cells are debatable. Although artemisinin-induced alterations in some tumor cells are consistent, it is not clear if this toxicity resides in defined molecular targets. Drug concentrations required to have an effect on cancer cells are often higher than those inducing toxicity in malaria parasites. Artemisinin, DHA, artesunate, and artemether exhibit $48 \mathrm{~h}$ $\mathrm{IC}_{50}$ s (fifty percent inhibitory concentration) up to $15 \mathrm{nM}$ in malaria parasites $[49,50]$, whereas their anticancer activity is cell-line dependent and $\mathrm{IC}_{50}$ s fluctuate between 0.5 and $\geq 200 \mu \mathrm{M}$ [5]. The exquisite sensitivity of malaria parasites to artemisinin points to the presence of specific parasitic targets. By contrast, in cancer cells, the artemisinin effect seems to be rather mediated by more general mechanisms through generation of ROS. However, it has been suggested that ROSmediated damage may be triggered by an initiating event in the vicinity of artemisinin activation [35]. Microscopy analyses in artesunate-treated cells have shown early oncosislike morphological changes at subcellular structures in which ROS generation may be triggered [51].
Microarray analyses found that the action of artemisinin seems to be modulated by the expression of oxidative stress enzymes including catalase, thioredoxin reductase, superoxide dismutase and the glutathione S-transferase family [5, 52]. Artemisinin-sensitive cells have downregulated oxidation enzymes whereas overexpression of these molecules renders cancer cells less sensitive [5]. Direct evidence in the HL-60 cell line has revealed that early and rapid generation $(1 \mathrm{~h})$ of ROS has been associated with apoptosis induction and artemisinin-induced damage. Furthermore, $\mathrm{IC}_{50}$ has been directly correlated with ROS levels [52]. Conversely, the action of artemisinin in several experimental systems has been reverted in presence of the antioxidant agents, $\mathrm{N}$-acetyl cysteine, and 1,2-dihydroxybenzene-3,5-disulfonic acid (TIRON, an iron scavenger), which resulted in a delay in cell death $[40,52,53]$. A recent study has demonstrated that generation of ROS in artesunate-treated HeLa cells (16h) occurring before cytotoxicity is being detected $(48 \mathrm{~h})$ [35], suggesting that this may be the starting event in artemisinininduced damage. The electron transfer chain (ETC) in the mitochondrion has been proposed to play a role in the generation of ROS, however substantial cytotoxicity is still detected in HeLa cells devoid of ETC indicating that other sources of ROS may be available in the cells [35]. Indeed, emerging evidence has postulated that oxidative stress in breast cancer cells is initially generated in the lysosome as consequence of iron-activated artesunate in a process 


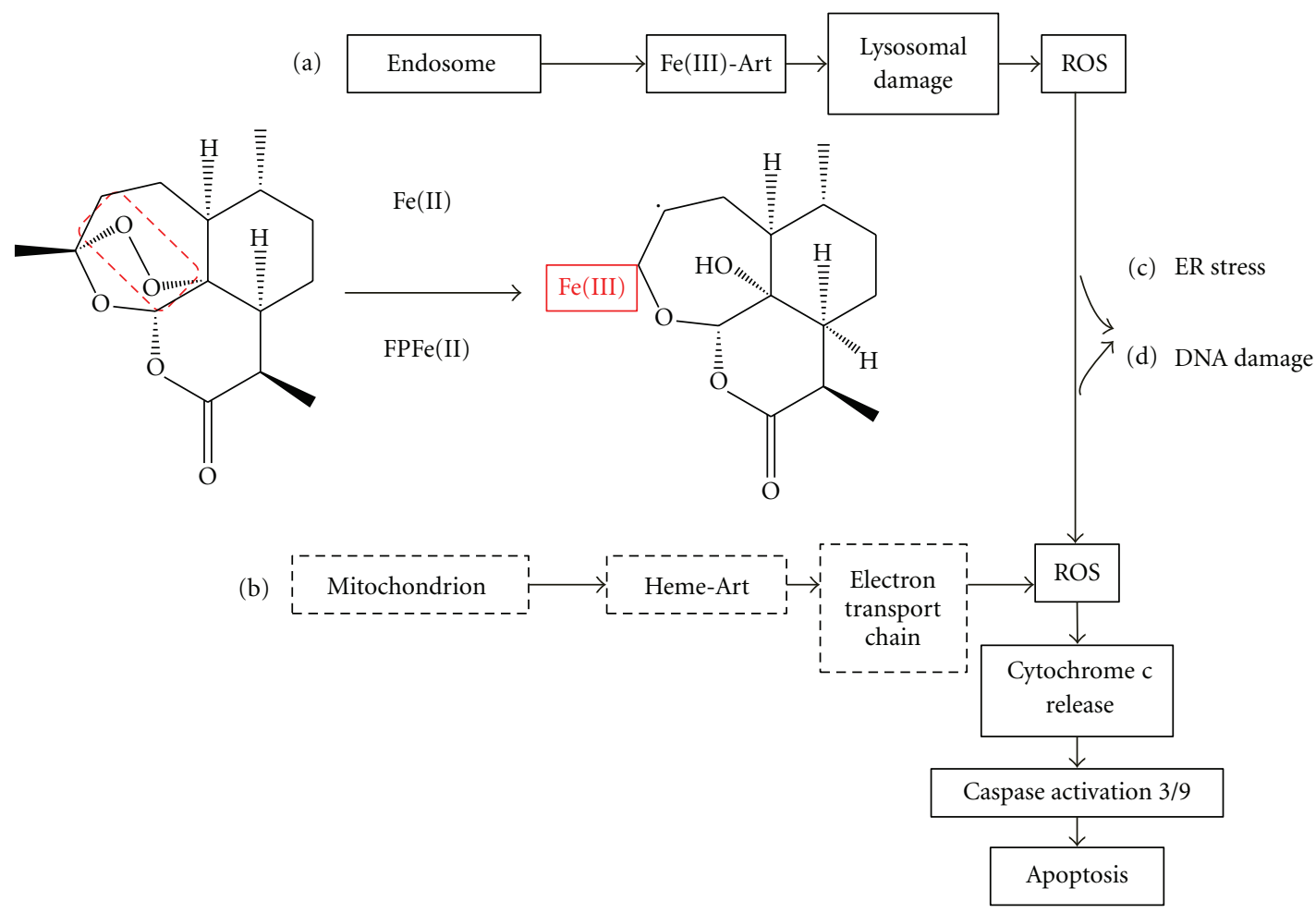

Figure 2: Postulated anticancer mechanisms of action of artemisinins. (a) It has been postulated that bioactivation of artemisinin occurs in the endosome after $\mathrm{pH}$-induced release of iron from internalized transferrin. Iron activated-artemisinin generates carbon-centered radicals which may mediate lysosomal disruption and generation of ROS resulting in mitochondrial damage, activation of caspases, and cell death. (b) Alternatively, it has been suggested that only specific activation of artemisinin by heme or heme-bound protein generates cytotoxiccarbon-centered radicals. In the mitochondrion, these adducts interfere with the electron transfer chain (ETC) by interacting with heme or heme-bound proteins leading to generation of ROS and apoptosis. (c) ROS harboring may induce ER stress and (d) genotoxicity.

similar to that suggested in malaria parasites [31]. Thus, activation of the mitochondrial intrinsic apoptotic pathway is a downstream event leading to cell death [31] (Figure 2). In this model, artemisinins may be negatively controlling heme synthesis and further increase cytotoxicity [31].

Despite the growing evidence of ROS-mediated damage in many cell systems $[31,33,35,54]$, cell damage has been also independently associated with oxidative stress [35]. Particularly, novel artemisinin dimers seem to exert antitumor action with little or no ROS generation, however the underlying mechanism of cytotoxicity is still under study [26]. It also remains unclear if artemisinins-induced necrosis may be a ROS-independent mechanism of cell death [35].

The antineoplastic toxicity of artemisinins appears to be also modulated by calcium metabolism [40, 55-57], endoplasmic reticulum (ER) stress $[33,40]$, and the expression of the translationally controlled tumor protein, TCTP, a binding calcium protein which has been also postulated as a parasite target [5]. Although the expression of the TCTP gen, tctp, was initially correlated with cancer cell response to artemisinins, a functional role for TCTP in the artemisinin action has yet to be found [58].

As for malaria parasites, the role of sarcoendoplasmic $\mathrm{Ca}^{2+}$ ATPase (SERCA) as artemisinin target in cancer cells has also been explored [40]. Previous evidence has revealed that treatment with $10 \mu \mathrm{M}$ artemisinin increases calcium concentrations as a result of SERCA inhibition [59]. However, studies on the mechanism of action of two artemisinin dimers have shown that potent ROS-mediated induced ERstress after treatment was independent of SERCA inhibition [40]. Interestingly, the behavior of a highly active artemisinin dimer and thapsigargin, a well-known SERCA inhibitor, seems to be similar but mediated by different molecular events [40]. In fact, thapsigargin lacks the endoperoxide moiety and only generates discrete ROS levels. Nevertheless the ER appears to be a relevant site for artemisinin action as in HepG2 cells a fluorescent derivative has been shown to preferentially accumulate in this cell compartment [60].

Artemisinins have shown pleiotropic effects through different experimental systems. It is also possible that the underlying mechanisms mediating artemisinins cytotoxicity may vary upon specific hallmarks or shifting characteristics in cancer cell lines (Table 1). This will be only possible to elucidate if the molecular events involved in countering malignant cell proliferation are investigated in different cell lines under similar conditions.

\section{Artemisinins as Anticancer Drugs}

4.1. Antitumor Effects of Artemisinin and Its Derivatives. Significant antitumor activity of artemisinin and licensed semisynthetic artemisinin derivatives has been documented 
TABLE 1: Factors that may influence artemisinins response in cancer cells.

\begin{tabular}{ll}
\hline System & Factor/characteristic \\
\hline & Proliferating activity \\
& Expression of transferrin receptors \\
& Accumulation levels of iron \\
& Levels of gene expression (i.e., proapoptotic and antiapoptotic genes) \\
& Shifting hallmarks \\
Cancer cell & Overexpression of potential molecular targets in some tumors \\
& Cellular dependence on redox balance \\
& Expression of antioxidant enzymes \\
& Expression of estrogen receptors in breast cancer cells \\
& Dose and time of exposure \\
& Chemical structure: number of trioxane rings, for example, dimeric compounds can be up to >1000 fold-more \\
potent than monomeric artemisinins [61] & In dimeric endoperoxides: nature and stereochemistry of the linker \\
Artemisinin & In novel compounds, electrophilic substitutions in the ring or those conferring lipophilicity. Boat/chair \\
& conformation \\
&
\end{tabular}

in vitro and in animal models. Considerable research has been focused on the most active compounds, namely, DHA and artesunate. One study that tested 55 cell lines from the Developmental Therapeutics Program of the National Cancer Institute (NCI) showed that artesunate displays inhibitory activity against leukemia, colon, melanoma, breast, ovarian, prostate, central nervous system (CNS), and renal cancer cells [5]. Dihydroartemisinin has also remarkable antineoplastic activity against pancreatic, leukemic, osteosarcoma, and lung cancer cells [62]. Moreover, artemisone has shown better activity than artemisinin and considerable synergistic interactions with other anticancer agents [63].

Artemisinin has been found to act either directly by inducing DNA damage (genotoxicity) or indirectly by interfering with a range of signaling pathways involved in several hallmarks of malignancy. However, direct DNA damage is only described in specific systems, while indirect effects are more commonly refereed in the literature. In pancreatic cells (Panc-1), artesunate caused DNA fragmentation and membrane damage. Interestingly, low doses of artesunate were associated with oncosis-like cell death, whereas higher concentrations induce apoptosis [51]. Extend and type of damage seem to depend on the phenotype and the origin of cell line, and it may also vary in a time- and dose-dependent manner (Table 1). Notably, higher sensitivity to artesunate was observed in rapidly growing cell lines when compared with slow growing cancer cells [5].

Alternatively, DHA, artesunate, and artemether are likely to modulate genes and proteins coordinating growth signals, apoptosis, proliferation capacity, angiogenesis and tissue invasion, and metastasis. A complex network of interactions through different pathways may enhance the anticancer effect of these endoperoxide drugs leading to cancer control and cell death (Table 2).

4.1.1. Artemisinins Counter Cancer Proliferative Capacity. In normal cells, cyclin-dependent kinases (CDK) are the proteins translating signals in order to push cell through the cell cycle. Normal growth relies on the ability to translate signals in order to replicate and divide in an effective manner [64]. Uncontrolled proliferation in cancer cells is the result of mutations inducing amplification of growth signals, deregulation of checkpoints, and loss of sensitivity to growth inhibitors [65]. Abnormal cell growth is also triggered by deregulation of programmed cell death or apoptosis [65]. Artemisinin and its semisynthetic derivatives are able to effectively induce cell growth arrest in cancer lines either by disrupting the cell cycle kinetics or by interfering with proliferation-interacting pathways. Dihydroartemisinin and artesunate are very potent growth inhibitors with multiple studies pointing to DHA as the most potent anticancer artemisinin-like compound (DHA $>$ artesunate $>$ arteeter $>$ artemether) $[5,66]$. Recently, artemisone has shown impressive antitumor efficacy in 7 cells lines including melanoma and breast cancer cells [63]. Artemisinin compounds have been shown to exert cytostatic and cytotoxic action on cancer cells $[63,67]$. Artemisinin-induced growth arrest has been reported at all cell cycle phases; however, arrest at $\mathrm{G}_{0} / \mathrm{G}_{1}$ to $S$ transition seems to be more commonly affected [5] (Table 2). Arrest at all cell cycle phases at the same time has been interpreted as a cytostatic effect [63]. Disruption of the cell cycle at $\mathrm{G}_{2} / \mathrm{M}$ was observed after DHA treatment in osteosacorma, pancreas, leukemia [68] and ovarian cancer cells [69] (Table 2). Similarly, artesunate interferes with $\mathrm{G}_{2}$ in osteosarcoma, ovarian, and other different cancer lines (Table 2). The underlying mechanisms of artemisinins-induced growth arrest include alterations in the expression and activity of regulatory enzymes of the cell cycle, such as CDK2-4 and -6 and D type cyclins ( $\mathrm{G}_{1}$-to-S-phase transition) or CDK1, and A-type cyclin $\left(\mathrm{G}_{2} / \mathrm{M}\right)$ [70-72]. The antiproliferative action of artemisinin induces downregulation of CDK transcription, inhibition of CDK promoters or increase of p21, p27, and CDK inhibitor [72] (Table 2). Inhibition of proliferation may be also attributed to downregulation of interacting proteins targeting multiple pathways [72]. It has 
TABLE 2: Antitumor effects of artemisinins.

\begin{tabular}{|c|c|c|c|c|}
\hline Cmpd & Cancer/cell line & Effect & Event/mechanism & Refs \\
\hline \multirow{2}{*}{ DHA/ART } & Osteosarcoma & Growth arrest & $\mathrm{G}_{2} / \mathrm{M}$, decreased survivin & {$[73]$} \\
\hline & $\begin{array}{l}4 \text { cell lines with different p53 } \\
\text { status }\end{array}$ & Apoptosis & $\begin{array}{l}\text { Increased Bax, activation of caspase } 3,8,9 \\
\text { Decreased } \mathrm{Bc} 12, \mathrm{Cdc} 25 \mathrm{~B} \text {, cyclin } \mathrm{B} 1, \mathrm{NF}-\kappa \mathrm{B}\end{array}$ & {$[44]$} \\
\hline \multirow[t]{2}{*}{ DHA } & Hepatoma (different cell lines) & Growth arrest & $\begin{array}{l}\mathrm{G}_{1}, \text { decreased cyclin D, E, CDK2-4, E2F1 } \\
\text { Increased Cip 1/p21, Kip 1/p27 }\end{array}$ & {$[67]$} \\
\hline & & Apoptosis & $\begin{array}{l}\text { Increased } \mathrm{Bax} / \mathrm{Bcl} 2 \text { ratio, activation of caspase } 3 \\
\text { Increased poly } \mathrm{ADP} \text {-ribose polymerase } \\
\text { Decreased } \mathrm{MDM} 2\end{array}$ & \\
\hline \multirow{2}{*}{ DHA/ART } & Neuroblastoma & Growth arrest & $\mathrm{G}_{1}$ & {$[52]$} \\
\hline & & Apoptosis & Activation of caspase 3 & \\
\hline \multirow{5}{*}{ DHA } & \multirow{5}{*}{ Pancreas (BxPC3 RFP) } & Growth arrest & $\mathrm{G}_{1}$, decreased cyclin $\mathrm{D} 1$, increased $\mathrm{p} 21$ & {$[74]$} \\
\hline & & Apoptosis & Increased Bax, decreased Bcl2 & {$[74,75]$} \\
\hline & & & Decreased VEGF & {$[75,76]$} \\
\hline & & Angiogenesis & Decreased NF- $\kappa$ B DNA binding & {$[74,76]$} \\
\hline & & & IL-8, COX2, MMP9 & {$[76]$} \\
\hline \multirow{4}{*}{ DHA } & Human promyelocytic & Growth arrest & $\mathrm{G}_{1}$ & {$[33,34]$} \\
\hline & Leukemia (HL-60) & Apoptosis & ER stress, degradation of c-MYC & {$[33]$} \\
\hline & Colorectal cancer (HT116) & & Increased GRP78 & {$[34]$} \\
\hline & & & DNA damage & {$[33]$} \\
\hline \multirow{3}{*}{ DHA } & Lung cancer (SPCA1) & & Decreased survivin & {$[56]$} \\
\hline & $(\mathrm{PC}-14)$ & Apoptosis & Increased calcium levels, increased p38 MAPK & {$[57]$} \\
\hline & (ASTC-a-l) & & $\begin{array}{l}\text { Increased oxidation, activation caspase } 3,9,8 \\
\text { Bax translocation }\end{array}$ & {$[54]$} \\
\hline \multirow{3}{*}{ DHA/ARS } & \multirow{3}{*}{$\begin{array}{l}\text { Human ovarian cancer (cell } \\
\text { panel, A2780, OVCAR-3) }\end{array}$} & Growth arrest & $\mathrm{G}_{2}$ & {$[69]$} \\
\hline & & \multirow{2}{*}{ Apoptosis } & Increased Bax-Bad, decreased Bclx-Bcl2 & {$[69,77]$} \\
\hline & & & Activation caspase $3 / 9$ pathway & {$[69,77]$} \\
\hline DHA & Lymphatic endothelial cells & Apoptosis & $\begin{array}{l}\text { Increased Bax, decreased Bcl2 } \\
\text { Decreased VEGFR-3/FL-4 }\end{array}$ & {$[78]$} \\
\hline DHA & Melanoma (A375, G361, LOX) & Apoptosis & $\begin{array}{l}\text { Increased oxidative stress, increased NOXA } \\
\text { Activation caspase } 3\end{array}$ & {$[79]$} \\
\hline DHA & Jurkat T Lymphoma & Apoptosis & $\begin{array}{l}\text { DNA damage } \\
\text { Increased oxidation, increased NOXA } \\
\text { Increased Bak, activation of caspase } 9\end{array}$ & {$[80]$} \\
\hline DHA & Fibrosarcoma (HT 1080) & Migration/invasion & $\begin{array}{l}\text { Decreased NF- } \kappa \mathrm{B}, \mathrm{AP}-1 \\
\text { Decreased activation of MMP2, MMP9 } \\
\text { Decreased PKC } \alpha / \text { Raf/ERK and JNK } \\
\end{array}$ & {$[81]$} \\
\hline DHA & Glioma cells (C6) & Apoptosis & Decreased HIF $1 \alpha$, VEGF & {$[41]$} \\
\hline \multirow{2}{*}{ DHA } & \multirow{2}{*}{$\begin{array}{l}\text { Chronic myeloid leukemia } \\
\text { (K562 cells) }\end{array}$} & \multirow{2}{*}{ Growth arrest } & $\mathrm{G}_{2}$, decreased PCNA, cyclin B1, D1, E1 & {$[82]$} \\
\hline & & & CDK2-4, E2F1, DNA-PK, DNA-topo1, JNK VEGF & {$[68]$} \\
\hline ART & & Angiogenesis & Decreased VECF & {$[82]$} \\
\hline \multirow[t]{2}{*}{ DHA } & \multirow[t]{2}{*}{ Lewis lung carcinoma } & \multirow[t]{2}{*}{ Angiogenesis } & $\begin{array}{l}\text { Decreased VEGF-C, IL-1 } \beta \text {-induced p38 } \\
\text { MAPK activation }\end{array}$ & [83] \\
\hline & & & Decreased VEGF receptor KDR/flk-1 & {$[84]$} \\
\hline DHA/ART & $\begin{array}{l}\text { Cervix carcinoma (HeLa) } \\
\text { Human papillomavirus } \\
\text { immortalized/transformed } \\
\text { cells }\end{array}$ & Apoptosis & Activation of caspase 9 & {$[85]$} \\
\hline ART & $\begin{array}{l}\text { Leukemia, melanoma, } \\
\text { non-small cell lung cancer, } \\
\text { colon, renal, ovarian, prostate, } \\
\text { CNS; prostate, breast cancer } \\
\text { (NIC cell panel) }\end{array}$ & Growth arrest & $\begin{array}{l}\mathrm{G}_{0} / \mathrm{G}_{1}, \text { decreased CDK } 2, \mathrm{CDC} 25 \mathrm{~A} \\
\mathrm{G}_{2} / \mathrm{M} \text {, decreased cyclin } \mathrm{B} 1\end{array}$ & {$[5]$} \\
\hline
\end{tabular}


TABle 2: Continued.

\begin{tabular}{|c|c|c|c|c|}
\hline Cmpd & Cancer/cell line & Effect & Event/mechanism & Refs \\
\hline \multirow{3}{*}{ ART } & \multirow{3}{*}{$\begin{array}{l}\text { Endometrial carcinoma } \\
\text { (HEC-1B) }\end{array}$} & Growth arrest & $\mathrm{G}_{0} / \mathrm{G}_{1}$ & \multirow{3}{*}[86]{} \\
\hline & & Apoptosis & Activation of caspase 3 , decreased COX-2 & \\
\hline & & Angiogenesis & Increased E-cadherin & \\
\hline ART & $\begin{array}{l}\text { Pancreatic cancer (BxPC3, } \\
\text { MiaPaCa-2) }\end{array}$ & Apoptosis & $\begin{array}{l}\text { Activation of caspases } 3,7 \\
\text { Inhibition of topoisomerase II a }\end{array}$ & {$[87]$} \\
\hline \multirow{4}{*}{ ART } & \multirow{4}{*}{$\begin{array}{l}\text { Non-small cell lung cancer } \\
\text { (SPC-A1) }\end{array}$} & \multirow{4}{*}{ Metastasis } & Decreased MMP2, transactivation of AP-1 & {$[56,88]$} \\
\hline & & & $\mathrm{NF}-\kappa \mathrm{B}$ & \\
\hline & & & uPA promoter & {$[88]$} \\
\hline & & & MMP7 & {$[56]$} \\
\hline ART & Colorectal (CLY, HT29, Lovo) & Metastasis & $\begin{array}{l}\text { Increased E cadherin } \\
\text { Decreased Wnt-signalling pathway }\end{array}$ & {$[89]$} \\
\hline \multirow{2}{*}{ ART } & \multirow{2}{*}{$\begin{array}{l}\text { Mouse myeloma cell line } \\
\text { SP } 2 / 0\end{array}$} & Growth arrest & $\mathrm{G}_{0} / \mathrm{G}_{1}$ & \multirow[t]{2}{*}[90]{} \\
\hline & & Apoptosis & Decreased NF- $\kappa \mathrm{B}$ p65, increased $\mathrm{I} \kappa \mathrm{B} \alpha$ & \\
\hline \multirow{5}{*}{ ARS } & \multirow{2}{*}{$\begin{array}{l}\text { Hepatocellular cancer cells } \\
\text { (HepG2, SMMC-7721) }\end{array}$} & \multirow[t]{2}{*}{ Metastasis } & Increased TIMP2, Cdc42, E cadherin & \multirow[t]{2}{*}[91]{} \\
\hline & & & Decreased MMP2 & \\
\hline & $\begin{array}{l}\text { Nasopharyngeal cancer lines } \\
\text { (CNE-1 and CNE-2) }\end{array}$ & Growth arrest & 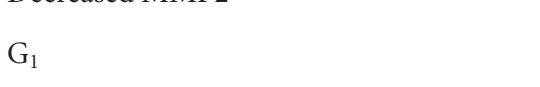 & {$[92]$} \\
\hline & \multirow{2}{*}{ Melanoma (A375P, A375M) } & Growth arrest & - & \multirow[t]{2}{*}[93]{} \\
\hline & & Migration & Decreased MMP2, $\alpha \mathrm{v} \beta 3$ integrin & \\
\hline \multirow{3}{*}{ ATM } & \multirow{2}{*}{ Colorectal (HCT116, SW480) } & \multirow{3}{*}{ Growth arrest } & $\mathrm{G}_{1}, \mathrm{~S}, \mathrm{G}_{2}$, decreased CDK1 & \multirow{3}{*}[63]{} \\
\hline & & & All phases & \\
\hline & Breast (MCF-7) & & $\mathrm{G}_{1}$, decreased CDK4, cyclin D1 & \\
\hline
\end{tabular}

Abbreviations: Cmpd: compound; DHA: Dihydroartemisinin; ART: artesunate, ARS: artemisinin, ATM: artemisone.

been shown that DHA treatment in pancreatic cells (BxPC3, AsPC-1) inhibits viability by decreasing levels of proliferating cell nuclear antigen (PCNA) and cyclin D with parallel increase in p21 [74]. Another study in the same system shows that DHA counters NF- $\kappa$ B factor activation leading to inhibition of its targets in the proliferation (c-myc, cyclin D) and apoptotic pathways (Bcl2, Bcl-xl) [94]. Downregulation of survivin, a protein modulating apoptosis and $\mathrm{G}_{2} / \mathrm{M}$ cell cycle progression [95], was observed after treatment with DHA in lung cancer cells (SPC-A1) [94]. A similar effect was described by Qiang et al. in artesunate- treated osteosarcoma cells [44]. In prostate cancer, DHA induces cell cycle arrest by disrupting the interaction of Sp1 (specificity protein 1) and the CDK4 promoter [96]. Dissociation of the Sp1-CDK4 complex promotes caspase activation and cell death. In addition one work has identified artesunate as a topoisomerase II, an inhibitor which inhibits growth by interaction with multiple pathways [87]. Overall, artemisinins seem to be interfering with several pathways that are common to different cancer entities.

4.1.2. Proapoptotic Effect of Artemisinins. Apoptosis is a widely studied mechanism in antitumor therapy as its manipulation is an effective strategy for cancer control. This cellular process is mediated by a balance between the Bcl 2 family genes, the proapoptotic $\mathrm{Bax}$, and the antiapoptotic $\mathrm{Bcl} 2$ and their effects on the mitochondria [97, 98]. An increase in the $\mathrm{Bax} / \mathrm{Bcl} 2$ ratio induces the release of cytochrome $\mathrm{c}$ followed by sequential activation of caspases and culminating with cell death [98].
Apoptosis is a common and rapid artemisinin-induced effect observed in many cancer and cell lines. Treatment with $200 \mu \mathrm{M}$ DHA in leukemia cells induced apoptosis after 1 hour of exposure [32]. Artemisinin sensitivity has been correlated to the level of expression of antiapoptotic (Bcl2) and proapoptotic genes (Bax) in a cancer cell line $[61,97,99]$ (Table 1). In general, the apoptotic effects of artemisinin have been attributed to activation of the intrinsic pathway. Hence, mitochondrial membrane damage is thought to have a pivotal role in the cascade of cell death events. Many studies have revealed that artemisinin-like compounds induce apoptosis by modulating the $\mathrm{Bax} / \mathrm{Bcl} 2$ ratio $[33,44,54,63,75,77,78$, 86, 99]. Consistent with these observations, DHA and artesunate, in a panel of osteosarcoma cells, caused cytochrome $\mathrm{c}$ release, Bax overexpression, increase in $\mathrm{Bax} / \mathrm{Bcl} 2$ ratio [44, 73], and activation of caspases 3 and 9. DHA also activates caspase 8 and decreases the levels of CDC25B, cyclin B1, and $\mathrm{NF}-\kappa \mathrm{B}$ [73]. In the same system, artesunate exposure depletes survivin which has also been involved in the apoptotic DHA response in lung cancer cells [56]. Similar events have been described in hepatoma cancer lines treated with DHA, particularly in this system DHA and the prototype drug artemisinin seem to have similar potency [67]. A microarray analysis has correlated the expression levels of c-MYC with enhanced DHA-induced apoptosis. Leukemia (HL-60) and colon cancer cells (HCT116) expressing high levels of c-MYC are significantly more sensitive to the DHA proapoptotic action. Moreover, knockdown of $c-m y c$ in HCT116 depleted DHA-associated cell death [33]. Downregulation of $c$-myc 
may also correlate with induced $\mathrm{G}_{1}$ arrest in this cell line [33]. Studies in metastatic melanoma (A375, G361 cell line) and Jurkat T lymphoma cells have associated the elevated apoptotic action of DHA with upregulation of NOXA (a proapoptotic protein), caspase 3 activation, and oxidative stress [79, 80]. In lung cells, the apoptotic effect of DHA occurs with increasing calcium concentration and activation of p38 [56, 57].

In some studies alterations on molecules acting on the extrinsic apoptotic pathway have also been described [54]. DHA seems to increase the transcription of the cell death receptor 5 (DR5) promoter and induces DR5 in different prostate cancer lines. In fact, a combination treatment with TRAIL, a DR5 ligand, strongly enhances DHA proapoptotic action by up to $35 \%$ on this system [100].

Artemisinins usually promote apoptosis rather than necrosis in most of the systems, however in some cases both apoptosis and necrosis have been reported. Induction of apoptosis is a major benefit of artemisinins' antitumor action as it prevents the collateral effects of inflammation and cell damage caused by necrosis. Artemisinin-induced necrosis has been associated with low levels of ATP and defective apoptotic mechanisms in some cell lines [35].

4.1.3. Artemisinins and Metastasis/Invasion Inhibition. The ability of malignant cells to invade has been associated with high mortality and morbidity in cancer patients. The spread of cancer cells to other organs is a process in which malignant cells readily invade through the extracellular matrix, reach and survive in the bloodstream, and finally seed at distant organs [101]. To achieve invasion, the cancer cell requires the loss of expression or function of E-cadherin, a calcium-binding transmembrane molecule involved in cellcell adhesion. A range of genes encoding extracellular matrix processing proteases, motility factors, and adhesion proteins are also acting at different steps in the metastatic process [101]. Recently, PAI-1 and TIMP-1 known as endogenous protease inhibitors have also been shown to be involved in cancer metastasis [102]. An invaluable benefit of artemisinin is its relevant antimigratory activity in highly aggressive and invasive cancer entities $[56,59,88,91]$. Antimetastatic activity of artemisinins has been correlated with modified expression of the matrix metalloproteinases (MMP) gene family and their effects on $\alpha v \beta 3$ integrins [93]. In hepatoma cells (HepG2 and SMMC 7721), treatment with $12.5 \mu \mathrm{M}$ artemisinin depleted migration linked to a decrease in MMP2 with concomitant increase in TIMP-2. Inhibition of metastasis is achieved as artemisinin increases cell-cell adhesion by enhancing E-cadherin activity and Cdc42 activation [91]. In addition, it has been found that some cancer cells may have specific proteins cointeracting at different pathways. For example, in non-small cell lung cancer [56] and fibrosarcoma, DHA treatment induced low levels of MMP2, MMP7, or MMP9 driven by AP- 1 and NF- $\kappa$ B transactivation or inactivation [81]. Previous studies have shown that MMP2 is regulated by Sp-1 transcription factor activity [103], moreover DHA-induced disruption of Sp-1 molecular interactions has been postulated as a crucial event for DHA regulation effects on different pathways [72]. Other investigations have found that in mouse lung Lewis cancer, lymphoid node metastasis and lymphangiogenesis were retarded by artemisininmediated inhibition of vascular endothelial growth factor $\mathrm{C}$ (VGF-C) [83].

4.1.4. Artemisinins and Angiogenesis Inhibition. As malignant tissues grow, metastases and solid tumors require extra blood supply for thriving and survival. Thus, cancer cells induce neovascularisation by regulating proteins and pathways involved in the generation and restructure of new vasculature [101]. Angiogenesis process leads to enhanced proliferation of endothelial cells through induction of vascular endothelial growth factor (VEGF), fibroblast growth factor (FGF), its receptors, and cytokines [101]. This event occurs via multiple mechanisms including hypoxia-driven activation of expression of HIF- $1 \alpha$ and the aryl hydrocarbon receptor nuclear translocator (ARNT) [104]. Angiogenesis control is mediated by angiostatin, endostatin, thrombospondin, TIMPs, PAI-1, and others [101]. Due to their role in tumor survival, the proangiogenic factors and the molecules involved in their regulatory networks are relevant drug targets. A microarray-based study revealed that artemisinins, artesunate and other derivatives inhibit neovascularisation by modulating gene expression of angiogenic factors [105]. Artemisinins responses seem to be mediated by downregulation of growth factors (VEGF, FGF) [82, 106], HIF- $1 \alpha$ [107], new vessel mediator angiogenin (ANG), the cysteine-rich angiogenic inducer (CYR61), some metalloproteinases (MMP9, MMP11, and BMP1), and collagens [105]. In parallel, artemisinins- induced upregulation of angiogenesis inhibitors was observed [105]. These findings have been supported by experimental investigation in different systems, unveiling other molecular interactions. Exposure of human umbilical vein endothelial cells to $50 \mu \mathrm{M}$ DHA prevents angiogenesis by depleting the levels of the VEGF flt-1 and KDR/flk1 -receptors. Similar effects were reproduced in lymphatic endothelial cells and Lewis lung carcinoma $[78,84]$. In pancreatic cells $(\mathrm{BxPc}-3)$ and $\mathrm{BalB} / \mathrm{c}$ nude mice, DHA induced inhibition of NF- $\kappa$ B DNA binding and downregulation of its angiogenic-related targets such as VEGF, IL-8, COX2, and MMP9 [76]. Reduced levels of NF- $\kappa$ B have been previously associated with proliferation and metastasis inhibition [33, $81,90,94]$ suggesting that $\mathrm{NF}-\kappa \mathrm{B}$ regulation may be a key role in the multimodal action of DHA in this system. NF- $\kappa \mathrm{B}$ is a crucial factor regulating multiple processes and it has a key role in the anticancer drug response. It is activated by DNA damage and it is a mediator of apoptosis resistance in response to drug pressure.

Other anticancer properties have also been attributed to artemisinins. Artesunate has shown its ability to revert cellular transitions allowing re-differentiation of tissues by negative control of Wnt-signaling pathway [89]. Notably, artesunate has been found to be more effective in less differentiated cell lines [89].

4.2. Antitumor Action of Artemisinins in Resistant Cancer Cells. One major obstacle for a successful anticancer therapy is the development of resistance over time. Many aggressive tumors become refractory to anticancer therapy with hardly 
any chemotherapeutic alternatives. A leading cause of drug resistance is the drug efflux generated by overexpression of membrane protein pumps, which results in ineffective low drug concentrations [108]. Anticancer activity of artemisinins has shown to be unaffected in otherwise resistant and multiresistant cancer cells. One study using the $55 \mathrm{NCI}$ cell lines and microarray analysis revealed that genes related with resistance to the established anticancer drugs such as MDR1 $(P g p), M R P 1$, and $B C R P$ showed no impact on the activity of artemisinins [5]. This was substantiated when no effects on the artesunate growth inhibition profile were observed in multidrug resistance HL-60 cell lines overexpressing MRP1 and $B C R P$-overexpressing cells, suggesting that antitumor activity of artemisinin is preserved when resistance to other agents is present [5]. Artemisinins are effective in a broad range of resistant cancer lines including doxorubicin, metrotexate, and hydroxyurea-resistant lines with no crossresistance [5]. Further investigation has shown that artesunate proapoptotic effect is not affected in a doxorubicinresistant leukemia cell line; instead artesunate potentiates doxorubicin apoptotic effects [4]. In another study, anticancer potency of artesunate is preserved in chemoresistant and chemosensitive neuroblastoma cell lines and primary neuroblastoma cultures [52]. In this system, sensitivity to artesunate was not affected in vincristin, doxorubicin, cisplastin, topotecan, mephalan, and ectoposide-adapted cells with $\mathrm{IC}_{50}$ s ranging from $1.4-2.7 \mu \mathrm{M}$ similar to that of the parent sensitive cell line [52]. Only one cell line showed low sensitivity to artesunate which was related to low ROS formation and increased expression of gluthatione cysteine ligase (GCL) [52]. Depletion of glutathione mediated by a GCL inhibitor improved artesunate sensitivity in this cell line [52]. P-glycoprotein (Pgp) or p53 attenuation did not affect sensitivity to artesunate [52]. DHA has shown the lowest $\mathrm{IC}_{50}$ in some cell lines such as cholangiocarcinoma (CL-6) and hepatocarcinoma (Hep G2) compared to other anticancer agents; moreover, upregulation of MDR1, MRP12, or MRP3 shows no effect on potency [109]. Lack of cross resistance between anticancer agents and artemisinins might be based on different mechanisms of drug action and/or resistance. Most of the conventional anticancer agents are nucleoside analogs, whereas artemisinins action is thought to be mediated by a ROS-dependent mechanism. Furthermore, in erythromyelogenous leukemia and human small cell lung cancer, artemisinins show no significant inhibition towards Pgp or MRP1 [4], thus in principle overexpression of protein pump may not affect artemisinin's potency. In another system however, artemisinin (the prototype drug) increases doxorubicin resistance by upregulating $m d r p$ through a mechanism that will be discussed later.

\subsection{Interactions of Artemisinins and Standard Anticancer} Chemotherapy: Artemisinin Combination Therapy (ACT) for Cancer? Existing anticancer therapies predominantly target cancer proliferation either with chemotherapeutic agents, ionizing radiation or direct toxicity on growth factor signaling pathways. In a combination therapy for cancer, the antineoplastic action of artemisinin may contribute to an independent antitumor activity with no additional side effects.
The benefits of combining artemisinins with other anticancer agents have been investigated showing that multifactorial action of artemisinin in different pathways may improve overall activity (synergism).

It has been reported that resistant cancer cell lines become sensitive by adding artemisinin to the conventional treatment (chemosensitization). Interestingly, DHA and artesunate have exhibited the strongest chemosensitizing/ synergistic effects $[4,110]$, whereas the prototype drug artemisinin shows only additive and antagonistic interactions (Table 3). DHA significantly improves the anticancer effect of gemcitabine, an anticancer drug used in pancreatic cancer which develops resistance over time. In vitro and in vivo analysis in pancreatic cells demonstrated a DHA-induced increase in growth inhibition and apoptosis by 4 - and 2 -fold, respectively, compared with those obtained with gemcitabine alone [94]. A dual action of DHA in potentiating gemcitabine activity and possibly counteracting resistance has been attributed to DHA inhibition of gemcitabine- induced NF$\kappa \mathrm{B}$ activation and subsequent action on its targets [94]. A similar effect has been shown in hepatoma cancer cell lines irrespective of their p53 status [67]. DHA synergistically enhances tumor growth inhibition by $45 \%$ when in combination with gemcitabine, whereas artemisinin, the prototype, only induces additive effects [94].

Consistent with this observation, a greater antitumor activity was observed when DHA was used in a combination with cyclosphosphamide in murine Lewis lung carcinoma cell line or in combination with cisplatin in non-small cell lung cancer A549 in mice [84]. In rat C6 glioma cells, addition of $1 \mu \mathrm{M}$ DHA increased by $177 \%$ the cytotoxic effect of temozolomide, a DNA-alkylating agent used in the treatment of brain cancer. Further investigation found that DHA promotes apoptotic and necrotic activity of temozolomide through ROS generation [107]. Recently, an enhancement of artesunate anticancer activity has been observed in different combination regimens. A striking synergy was achieved in combinations of artesunate and the immunomodulator drug, lenalidomide [111].

However, the benefits of an artemisinin combination therapy need to be carefully dissected. Therapeutic effects are influenced by the mode of action of the drugs and multiple interactions in particular systems and schedules. Recently, Gravetth et al. showed that gemcitabine has only additive effects when combining gemcitabine and artemisone in colon and breast cancer cells [63]. In cancer colon cells (HT-29), it has been suggested that artemisinin may impair doxorubicin activity possibly by countering the doxorubicin effect on NF- $\kappa$ B inhibition [59]. The same authors have reported artemisinin-induced resistance in the same system through a different mechanism. Thus, it has been postulated that artemisinin exposure inhibits SERCA with subsequent accumulation of calcium. As a result, Pgp is upregulated and leads to generation of doxorubicin resistance cells [59]. By contrast, pretreatment with a calcium chelator reverted the cells to a sensitive phenotype [59]. Notably, DHA and artesunate have not been evaluated in this system; it remains to be elucidated whether the most potent chemosensitizers have similar effects on this cell line. So far, artesunate or DHA 
TABLE 3: Drug interactions of artemisinins.

\begin{tabular}{|c|c|c|c|}
\hline Drug combination & Cancer/cell line & Effect & Refs \\
\hline DHA + Temozolomide & Rat C6 glioma cells & $\begin{array}{l}\text { Increased apoptosis, ROS } \\
\text { Induced necrosis }\end{array}$ & {$[107]$} \\
\hline DHA + Cyclophosphamide & Lewis lung carcinoma & $\begin{array}{l}\text { Increased apoptosis, decreased VEGF receptor } \\
\text { KDR/flk-1 } \\
\text { Apoptosis }\end{array}$ & {$[84]$} \\
\hline DHA + Cisplatin & $\begin{array}{l}\text { Human non-small cell lung } \\
\text { cancer (A549) }\end{array}$ & Decreased metastasis & {$[84]$} \\
\hline \multirow[t]{2}{*}{ DHA + Gemcitabine } & Pancreas (Panc-1) & $\begin{array}{l}\text { Inhibition of proliferation, decreased cyclin D1 } \\
\text { Increased apoptosis, increased } \mathrm{Bax} / \mathrm{Bcl} 2 \text { ratio, } \\
\text { activation of caspase } 3\end{array}$ & {$[94]$} \\
\hline & Hepatoma (cell panel) & Increased growth inhibition by $45 \%$ & {$[67]$} \\
\hline DHA + Butyric acid & $\begin{array}{l}\text { Human lymphoblastoid } \\
\text { leukemia (Molt-4) }\end{array}$ & Synergistic. Depletion of cancer cells & {$[110]$} \\
\hline DHA + Radiation & $\begin{array}{l}\text { Glioma cells } \\
\text { U373MG }\end{array}$ & $\begin{array}{l}\text { Increased cytotoxicity } \\
\text { Inhibition of radiation-induced GST }\end{array}$ & {$[53]$} \\
\hline DHA + Carboplatin & $\begin{array}{l}\text { Ovarian cancer cells } \\
\text { (A2780, OVCAR-3) }\end{array}$ & $\begin{array}{l}\text { Increased growth inhibition through death receptor } \\
\text { and mitochondrial mediated pathways }\end{array}$ & {$[77]$} \\
\hline DHA + TRAIL & $\begin{array}{l}\text { Prostate cancer (DU145, } \\
\text { PC-3, LNCaP) }\end{array}$ & Increased apoptosis extrinsic and intrinsic pathways & {$[100]$} \\
\hline $\begin{array}{l}\text { ART/DHA + Doxorubicin } \\
+ \text { Pirarubicin }\end{array}$ & $\begin{array}{l}\text { Leukemia (K562/adr) } \\
\text { Small cell lung cancer } \\
\text { (GLC4/adr) }\end{array}$ & Synergistic & {$[4]$} \\
\hline ART + Lenalidomide & $\begin{array}{l}\text { Lung (A549) and breast } \\
\text { (MCF-7) }\end{array}$ & Decreased IC50 by $48 \%$ & {$[111]$} \\
\hline ART + Oxiplatin & Colon (HT 1116) & Additive. Sensitising effect & \\
\hline ART + Gemcitabine & $\begin{array}{l}\text { Breast (MCF-7) } \\
\text { Lung (A549) }\end{array}$ & $\begin{array}{l}\text { Additive } \\
\text { Additive }\end{array}$ & {$[111]$} \\
\hline $\begin{array}{l}\text { ATM + Oxiplatin } \\
\text { ATM + Thalidomide } \\
\text { ATM + Gemcitabine }\end{array}$ & $\begin{array}{l}\text { Colon (HCTl16, SW480) } \\
\text { Breast (MCF-7) }\end{array}$ & All additive & {$[63]$} \\
\hline $\begin{array}{l}\text { ARS + Hyperbaric oxygen } \\
\left(\mathrm{HBO}_{2}\right)\end{array}$ & Molt-4 human leukemia & $22 \%$ decrease in growth & [112] \\
\hline ARS + Doxorubicin & Colon cancer(HT29) & $\begin{array}{l}\text { Predicted as antagonic, mediated by activation of } \\
\text { NF- } \kappa \text { B/overexpression of Pgp }\end{array}$ & {$[59]$} \\
\hline ARS + Oxiplatin & Colon (HCTl16 SW480) & Antagonism & \\
\hline ARS + Thalidomide & Colon (HC1116, SW480) & Additive & {$[63]$} \\
\hline ARS + Gemcitabine & Breast (MCF-7) & Antagonism & \\
\hline
\end{tabular}

Abbreviations: $\mathrm{HBO}_{2}$ : hyperbaric oxygen.

in combination with doxorubicin and pirarubicin showed chemosensitizing effect in leukemia and human-small-cell cancer-resistant cell lines, but no further increase of sensitivity was observed in the sensitive parent cell lines [4]. The chemosensitising effect was independent of Pgp inhibition [4]. Overall, this evidence suggests that DHA and artesunate have remarkable ability to potentiate antitumor agents and to counter tumor resistance.

Artemisinins also improve ionizing-based therapies. In glioma cells U373MG, DHA treatment inhibits the radiation-induced expression of GST with concomitant ROS generation. A combination treatment with DHA has been shown to be more effective than radiation or DHA alone [53]. The adjuvant effect of artemisinin in other cancer treatments including hyperbaric oxygen has also been reported [112].
4.4. Artemisinin Resistance. A salient feature of artemisinin is that artemisinin resistance in vitro or in the field has yet to be confirmed after 30 years of use as an antimalarial. Clinically, tolerance has been reported in patients with therapeutic failure. However, in vitro tolerant strains are usually unstable and only develop after several years of continuous drug exposure [113]. The multimodal action of artemisinins at different cancer pathways might also predict a delay of induced resistance in malignant cells. Indeed, only few cell lines have shown intrinsic low sensitivity or no response to artemisinin or its derivatives. For example, artemisinin (the prototype drug) seems to be less active in breast cancer cells (MCF-7) and gastric cancer (MKN) [93]. Some studies in breast cancer cells have suggested that artemisinin response may be mediated by estrogen receptors (ER $\alpha$ and ER $\beta$ ) which 
are involved in cell proliferation (reviewed in [72]). Interestingly, it has been documented that in breast cancer cells, disruption of iron metabolism may enhance potency of doxorubicin and cisplatin [114]. The low response to artemisinin has been also associated with overexpression of BMI-1 in highly metastatic nasopharyngeal cancer cell lines (CNE-1, CNE-2) [92]. A recent study found some levels of cross resistance to artesunate and DHA in a unique cisplatin chemo-resistant cell line. This effect was partially reverted by L-buthionine-S,R-sulfoximine, an inhibitor of the antioxidant GLC [52].

However, in vitro resistance has already been developed under experimental conditions. Microarray and experimental studies using knockouts and transfected cells indicate that upregulation of the tumor suppressor $\mathrm{p} 16^{\mathrm{INK} 4 \mathrm{~A}}$ and the antioxidant protein, catalase, may confer resistance to artesunate independent of the p53 status [115]. Recently, concerns have arisen after Baechmeier et al. showed that a $24 \mathrm{~h}$ preincubation with $20 \mu \mathrm{M}$ artesunate induces resistance in highly metastatic breast cancer cells. Pretreated MDA-MB231 metastatic cells were completely refractory to further artesunate treatment, whereas a similar treatment in MDAMB-468, a non-metastatic cell line, renders less sensitive cells. Further investigation on the mechanism of artesunateacquired resistance indicates that upregulated transcription of NF- $\kappa \mathrm{B}, \mathrm{AP}-1$, and NMP-1 overcome artesunate apoptotic and antimetastatic action and allows tumor progression [116]. It is not clear, however, whether artesunate-induced resistance and loss of sensitivity are preserved after longterm cell subculturing. It also remains to elucidate if other semisynthetic endoperoxides may induce a similar effect or whether a combinational therapy may delay or revert the effect on cell lines bearing this phenotype.

4.5. Artemisinins Toxicity. Dose-dependent toxicity is a major drawback that hampers anticancer therapy. This problem may be overcome by enhancing anticancer activity and thus reducing toxic drug concentrations. DHA is the most active and neurotoxic artemisinin derivative [117]. Neurotoxicity has been reported in animal studies in a dose- and time-dependent manner ( $\geq 7$ days) [118-120]. The toxicity of artemisinin-like compounds has been associated with long-term availability, whereas short-term peak concentrations are not toxic [121]. Thus, rapid elimination of artemisinin in oral formulations is safer than slow-release or oil-based intramuscular formulations $[6,121]$. Remarkably, although artemisinins derivatives have been widely used as antimalarials, their toxicity in humans have been shown to be negligible. In cancer therapy, artemisinin may have multiple benefits as it can be used in combination with no additional side effects, but also it enhances potency and reduces doses of more toxic anticancer partners. Clinical doses used in malaria treatment after administration of $2 \mathrm{mg} / \mathrm{kg}$ in patients rise plasma concentrations of $2640 \pm 1800 \mu \mathrm{g} / \mathrm{mL}$ (approximately $6.9 \pm 4.7 \mathrm{mM}$ ) which can be considered up to 3 orders of magnitude higher than those artemisinin concentrations with antitumor activity [5]. It becomes relevant to closely monitor the safety of long-term artemisinin-based therapies as severe side effects may be highly unusual but significant.
So far, artemisinin treatments for as long as 12 months have been reported with no relevant side effects $[30,122,123]$. However, an extremely rare case of toxic brainstem encephalopathy was described in a patient after a 2-week herbal/ artemisinin combination $(400 \mathrm{mg}$ ) regimen for breast cancer [124]. Brainstem neurotoxicity has been reported in animal studies and associated with long-term ( $>28$ days) and highdose treatments [118]. Recently, a fatal case of overdosing in a child who was taking antimalarial treatment was reported [125].

4.6. Artemisinins in Clinical Trials. Antitumor activity of artemisinin has also been documented in human trials [126] and individual clinical cases $[30,122]$. Artemether and artesunate have been used in cancer therapy with good tolerability and lack of significant side effects.

Artesunate was successfully used in the treatment of laryngeal squamous cell carcinoma and substantially reduced the size of the tumor (by 70\%) after two months of treatment [122]. Furthermore, artesunate increased survival and substantial metastasis reduction when used in combination with standard chemotherapy in patients with malignant skin cancer [30]. Another report describes a beneficial improvement in a patient with pituitary macroadenoma who was treated with artemether for 12 months [123]. Artemether has longer half-life and easily crosses the blood-brain barrier which is crucial for brain tumor treatment.

Similarly, a clinical trial in 120 patients with advanced non-small cell lung cancer has shown that artesunate in combination with a chemotherapy regimen of vinorelbine and cisplatin elevated 1 -year survival rate by $13 \%$ with a significant improvement in disease control and time to progression [126]. No additional artesunate-related side effects were reported [126]. In Germany, a trial in patients with advanced breast cancer is currently ongoing. Tolerability to a combination therapy of 4-week artesunate will be assessed in this trial. Another trial in UK in colorectal adenocarcinoma to evaluate anticancer action and tolerability of artesunate was completed last year, but the results have not been published.

\section{Anticancer Action of Novel Artemisinins Derivatives}

5.1. Novel Semisynthetic Derivatives with Antitumor Action. Imperative need of highly effective compounds with enhanced pharmacological properties has led to the design of novel endoperoxide compounds with selective toxicity toward cancer cells. Considerable progress has been made in the design of novel compounds with enhanced potency at the nanomolar range, increased selectivity, and low toxicity in vitro. It has been reported that triazolyl substituted artemisinins-induced significant growth inhibitory effect [127]. Independent of stereo- or region-chemistry, strong inhibition was influenced by the functional group attached to the triazole ring. Substituted compounds with a penthyl benzene group showed the highest antiproliferative activity ranging from 0.07 to $0.39 \mu \mathrm{M} 72 \mathrm{~h} \mathrm{IC}_{50}$ in 6 cancer lines [127]. Recently, Feng et al. synthesized a series of dihydroartemisinin derivatives via an aza-Michael addition reaction with high selectivity index and 
$\mathrm{IC}_{50}$ in the nanomolar range against HeLa cells $(0.37 \mu \mathrm{M})$ [128]. In a series of deoxoartemisinins and carboxypropyldeoxoartemisinins, antitumor effect was associated with boat/chair conformations and drug-receptor interactions [129].

Different from their antiparasitic activity, it has been found that dimeric and trimeric artemisinin derivatives display much higher antitumor activity than their monomeric counterparts. In the last decade, an increase in the number of outputs in artemisinin dimeric compounds with anticancer activity has been observed. These compounds have shown $\mathrm{IC}_{50}$ ranging from 0.014 to $6 \mu \mathrm{M}[130,131]$. Potent anticancer toxicity has been correlated with the nature of the linker [132] and with lipophilicity or electrophilic substitutions [66]. Posner et al. developed a series of artemisinin-trioxane derivate dimers from which two phosphate esters displayed nanomolar growth inhibitory values in the NCI 60 human cell line screen. Further investigation in vitro showed that in HL-60 cells, these compounds are more potent than doxorubicin, whereas their strongly anti-parasitic monomeric counterparts showed no anticancer activity. As suggested by the authors, two trioxane units in addition to the nature of the linker may be relevant in conferring potent anticancer activity [132]. Homodimers of artesunic acid have also nanomolar inhibitory values when tested in chemo-resistant and sensitive leukemia cells. Notably, the artesunic dimer seems to be 6-fold more potent in the multiresistant Pgp overexpressing cells (CEM/ADR500) than in its sensitive counterparts. Anticancer activity was attributed to apoptosis induction, arrest of cell cycle at $\mathrm{G}_{0} / \mathrm{G}_{1}$, and ROS generation [131]. In prostate cancer cells (LNCaP, TRAMP CIA, and $\mathrm{C} 2 \mathrm{H}$ ), two $\mathrm{C} 10$ non-acetal trioxane dimers displayed a 3-fold increase in potency compared to doxorubicin (17-18 nM versus $45.3 \mathrm{nM}$ resp.). The dimers induced arrest at $\mathrm{G}_{0} / \mathrm{G}_{1}$ mediated by decreasing cyclin D1, cyclin E, CDK2, and an increase in $\mathrm{p} 21$ and $\mathrm{p} 27$. They also show proapoptotic action through upregulation in Bax expression [130].

In many studies, there has been an emphasis on the nature and stereochemistry of the dimer linker which may influence anticancer activity. However, it has also been shown that the linker by its own is inactive. Morrisey et al. have described that an artemisinin dimer exhibits up to 30 -fold more activity than artemisinin in prostate cancer lines [61]. This dimer selectively exerted highly antigrowth potential and apoptosis in C4-2 (a cell line derived from LNCaP) and LNCaP cells compared to artemisinin [61]. An enhanced anticancer activity seems to be given by the stereoisomery of the linker [130]. In another study, C12 non-acetal dimers and one trimer of deoxoartemisinin showed similar potency to that of the conventional anticancer drugs against many cell lines. The linker with one amide or one sulfur-centered 2 ethylene groups was essential for potent anticancer activity [133]. Diastomeric-cholic-acid-derived 1,2,4,5-tetraoxanes were also tested and found to have high anticancer activity against human melanoma (Fem X), and cervix cancer (HeLa) [134] cis stereoisomers were twofold more active. The authors further suggested that an amide terminus in the linker confers increased anticancer activity.
Interestingly, Beckman et al. showed that the stereochemistry of the ether linkage of the dimers, of dihydroartemisinin (diDHA), and dihydrodeoxyartemisinin (the respective endoperoxide lacking dimer) was as important for antitumor activity as the endoperoxide moiety. Dimers were tested against 60 cells from 9 different cancers showing that although in general the diDHA was more active than dihydrodeoxyartemisinin toward anticancer growth, asymmetrical dimers of either diDHA or dihydrodeoxyartemisinin were similarly toxic [26]. The mechanism underlying the antiproliferative action of the artemisinin-derived dimers needs further study.

Recently, a series of potent artemisinin-like derivatives of easy synthesis and anticancer activity has been identified. These endoperoxides exhibit high chemical stability and greater cytotoxicity than artesunate. These compounds also exhibit relevant antiangiogenic properties as judged by studies in a zebrafish model [135].

5.2. Fully Synthetic Artemisinins. It is important to recall that some limitations of artemisinins such as short half-life (between 1 and 5 hours [136, 137]), limited affordability, and solubility need to be further addressed. Although semisynthetic compounds have partially overcome these issues, they still rely on the availability of natural precursors. In malaria, some trioxolanes and ozonides with remarkable improved pharmacokinetics are under clinical development [138]. Recently, it has been found that synthetic trioxolanes with enhanced pharmacokinetic properties may exhibit a similar toxicity than artesunate in Schistosomas [139]. Given that artemisinins may be potentially used as anticancer drugs and possibly in other parasitic and viral infections, the development of novel compounds with enhanced pharmacokinetic properties and targeted anticancer actions is also paramount. Although novel semisynthetic artemisinins have shown substantial antineoplastic activity, there is still limited information regarding the cytotoxicity of fully synthetic endoperoxides. A series of tetraoxacyclohexanes have been shown to potentially exhibit anticancer properties. A triol substituted compound has displayed prominent antitumor action in vivo toward melanoma (LOX IMVI) and ovarian (IGROV1) cancer in nanomolar concentrations ( $\left.\mathrm{LC}_{50} 60 \mathrm{nM}\right)$ [140]. Other authors have synthesized compounds with dual action (antimalarial/anticancer effect). These deoxycholic-acid-(DCA-) —and cholic acid (CA)—derived mixed tetraoxanes are cytotoxic at very low concentrations and particularly potent against melanoma cancer (LOX IMVI, LC $_{50}$ up to $69 \mathrm{nM}$ ) [141].

\section{Future Development of Artemisinins as Anticancer Drugs}

Artemisinins have been recommended and widely used as antimalarials for several years [142]. This drug class has shown many biological activities, in particular, strong anticancer growth activity. Supporting evidence indicates that artemisinin-like compounds may be a therapeutic alternative in highly metastatic and aggressive cancers [44] with no longterm effective therapy $[44,61]$ and commonly developing 
drug resistance [94]. Furthermore, antimalarial endoperoxides may act synergistically with other anticancer drugs with no additional side effects [143].

6.1. What Do We Need to Know? The ability of artemisinins to kill cancer cells through multiple and heterogeneous molecular events has been well documented. However, some questions about the molecular base of artemisinin-induced cell death need further study. Growing research has been focusing on determination of the mechanism of bioactivation and molecular events underlying the artemisinin effects. However, how the antitumor activity is exerted following artemisinin activation is still not well understood. So far, the precise molecular events involved in how, when, and where ROS production is initially triggered in cancer cells remain to be defined. In addition, the relevance of any ROS- independent mechanism should be also addressed; these might not be obvious but possibly important for artemisinin cytotoxicity in some cancer cells. Some other aspects such as the direct DNA damage induced by artemisinin-like compounds and the role of p53 status in genotoxicity need to be further analysed.

One relevant aim in anticancer therapy is cotargeting multiple pathways minimizing shifting cell hallmarks and side effects. Whereas it remains important to characterize the anticancer effects of existing and novel artemisinins derivatives, research also needs to be focused on unveiling the mechanisms of cytotoxicity by identifying their relation to a particular cancer biomarkers and molecules. Artemisinins seems to regulate key players participating in multiple pathways such as NF- $\kappa$ B, survivin, NOXA, HIF- $1 \alpha$, and BMI- 1 . These molecules and others are to be revealed, which in turn may be involved in drug response, drug interactions, mechanisms of resistance, and collateral effects in normal cells. A better understanding of common mechanisms under similar conditions in different cell systems will greatly aid the development of targeted artemisinin derivatives. This will improve artemisinins cytotoxicity by lowering $\mathrm{IC}_{50}$, emerging of resistance, drug associated toxicity, and potentiating drug interactions.

It is important to connect the molecular interactions and the regulatory effects of artemisinin on the cancer hallmarks and particularly in those tumors with poor prognosis. Some cancer cell biomarkers may be potentially useful to predict success on an artemisinin-based treatment in specific systems. Furthermore, novel endoperoxide compounds and combinational therapies can be addressed to target or cotarget markers of carcinoma progression and prevent invasiveness and metastatic properties in highly recurrent and aggressive tumors or advanced stage cancers.

Although the benefits of artemisinins in the clinical setting have been already assessed, specific interactions with established chemotherapy need to be further dissected in different cancer cells and their phenotypes. This will be crucial to implement clinical trials and treatment of individual cases. In this regard, long-term therapy with artemisinins also requires close monitoring. It is important to note that the prototype drug, artemisinin, seems to modulate responses leading to antagonistic interactions with other anticancer drugs. However, whereas it may be useful to have the prototype drug as a control in vitro, its pharmacokinetic properties may differ from the semisynthetic artemisinins. Therefore, artemisinin antagonistic reactions and resistance must be cautiously validated using different semisynthetic derivatives. DHA, artesunate, and artemether are the endoperoxides currently licensed for therapeutic use. So far, artemether has been shown to share similar anticancer properties than DHA and artesunate [144].

Cancer research drives a permanent discovery of new genes and interactions. The study of how artemisinin drives tumor control may become even more complex as immunological hallmarks are also involved in the generation of tumors. Immunological hallmarks in cancer cells include the ability to induce chronic inflammatory response, evasion of tumor recognition, and ability to induce tolerance [145]. Whether artemisinin may participate in the mechanisms involved in these events has yet to be determined.

Overall, the real potential and benefits of the artemisinin drug class remain yet to be uncovered. The imminent possibility of artemisinins being included in the arsenal of anti cancer drugs has opened the door for challenging research in this area, one that seems to fulfill many expectations.

\section{Abbreviations}

ADP-ribose polymerase: Adenosine diphosphate ribose polymerase

AP-1: Activator protein 1

BAK: Proapoptotic member of the

BAX:

BCL2:

BCRP:

BCLX:

CDC25B: BCL2 protein family BCL2-associated protein

B-cell lymphoma 2

Breast cancer resistant protein gen Bcl-2-like protein 1

Dual specific phosphatase involved in the activation of

CDK:

Cip 1/p21:

cyclin-dependent kinases

Cyclin-dependent kinase

Cyclin-dependent kinase

inhibitor 1

CDC25A:

Dual specific phosphatase involved in the activation of

COX2:

Cdc42:

c-MYC:

DNA-PK:

DNA topo 1:

E2F1:

ER:

GST:

GRP78:

HIF $1 \alpha$ :

$\alpha \mathrm{v} \beta 3$ integrin:

cyclin-dependent kinases

Cyclooxygenase 2

GTPase of the Rho family

Transcription factor

DNA-dependent protein kinase

DNA topoisomerase 1

Transcription factor

Endoplasmic reticulum

Glutathione S-transferase

$78 \mathrm{kDa}$ glucose-regulated protein Hypoxia-inducible factor 1 alpha

Transmembrane heterodimeric protein expressed on sprouting endothelial cells

$\mathrm{I} \kappa \mathrm{B} \alpha:$

IL-1 $\beta$ :
Inhibitor of NF- $\kappa$ B

Interleukin 1 beta 


\begin{tabular}{|c|c|}
\hline IL8: & Interleukin 8 \\
\hline JNK: & Jun N-terminal kinase \\
\hline Kip1/p27: & $\begin{array}{l}\text { Cyclin-dependent kinase inhibitor } \\
\text { 1B }\end{array}$ \\
\hline KDR: & $\begin{array}{l}\text { Kinase insert domain protein re- } \\
\text { ceptor }\end{array}$ \\
\hline MMP: & Matrix metalloproteinase \\
\hline$M R P 1:$ & $\begin{array}{l}\text { Multidrug resistance-associated } \\
\text { protein gene }\end{array}$ \\
\hline MDM2: & $\begin{array}{l}\text { Murine doble minute oncogene } \\
\text { protein }\end{array}$ \\
\hline NK- $\kappa \mathrm{B}:$ & $\begin{array}{l}\text { Nuclear factor of kappa light poly- } \\
\text { peptide gene enhancer in B cells }\end{array}$ \\
\hline NOXA: & $\begin{array}{l}\text { Proapoptotic protein, a member } \\
\text { of the BH3-only Bcl-2 protein fa- } \\
\text { mily }\end{array}$ \\
\hline p38-MAPK: & Mitogen-activated protein kinase \\
\hline PAI-1: & Plasminogen activator inhibitor 1 \\
\hline PCNA: & Proliferating cell nuclear antigen \\
\hline PKCa: & Serine/threonine kinase \\
\hline ROS: & Radical oxygen species \\
\hline Raf/ERK: & Signaling pathway \\
\hline uPA: & Urokinase plasminogen \\
\hline TIMP2: & $\begin{array}{l}\text { Tissue inhibitor of metalloprotei- } \\
\text { nases }\end{array}$ \\
\hline TRAIL: & $\begin{array}{l}\text { The tumor necrosis factor-related } \\
\text { apoptosis-inducing ligand }\end{array}$ \\
\hline VEGF: & Vascular endothelial growth factor \\
\hline VEGFR-3/FL-4: & $\begin{array}{l}\text { Vascular endothelial growth factor } \\
\text { receptor }\end{array}$ \\
\hline Wnt: & Wingless-type signaling pathway. \\
\hline
\end{tabular}

\section{References}

[1] W. L. W. Hsiao and L. Liu, "The role of traditional Chinese herbal medicines in cancer therapy from TCM theory to mechanistic insights," Planta Medica, vol. 76, no. 11, pp. 1118-1131, 2010.

[2] T. Efferth, H. Dunstan, A. Sauerbrey, H. Miyachi, and C. R. Chitambar, "The anti-malarial artesunate is also active against cancer," International Journal of Oncology, vol. 18, no. 4, pp. 767-773, 2001.

[3] H. J. Woerdenbag, T. A. Moskal, N. Pras et al., "Cytotoxicity of artemisinin-related endoperoxides to Ehrlich ascites tumor cells," Journal of Natural Products, vol. 56, no. 6, pp. 849856, 1993.

[4] P. Reungpatthanaphong and S. Mankhetkorn, "Modulation of multidrug resistance by artemisinin, artesunate and dihydroartemisinin in K562/adr and GLC4/adr resistant cell lines," Biological and Pharmaceutical Bulletin, vol. 25, no. 12, pp. 1555-1561, 2002.

[5] T. Efferth, A. Saverbrey, A. Olbrich et al., "Molecular modes of action of artesunate in tumour cell lines," Molecular Pharmacology, vol. 64, no. 2, pp. 382-394, 2003.

[6] T. Gordi and E. I. Lepist, "Artemisinin derivatives: toxic for laboratory animals, safe for humans?" Toxicology Letters, vol. 147, no. 2, pp. 99-107, 2004.

[7] A. M. Dondorp, F. Nosten, P. Yi et al., "Artemisinin resistance in Plasmodium falciparum malaria," New England Journal of Medicine, vol. 361, no. 5, pp. 455-467, 2009.
[8] Qinghaosu Antimalaria Coordinating Research Group, "Antimalaria studies on Qinghaosu," Chinese Medical Journal, vol. 92, no. 12, pp. 811-816, 1979.

[9] M. Ashton, N. D. Sy, N. van Huong et al., "Artemisinin kinetics and dynamics during oral and rectal treatment of uncomplicated malaria," Clinical Pharmacology and Therapeutics, vol. 63, no. 4, pp. 482-493, 1998.

[10] Q. Li, P. J. Weina, and W. K. Milhous, "Pharmacokinetic and pharmacodynamic profiles of rapid-acting artemisinins in the antimalarial therapy," Current Drug Therapy, vol. 2, no. 3, pp. 210-223, 2007.

[11] R. K. Haynes, H. W. Chan, M. K. Cheung et al., "C-10 ester and ether derivatives of dihydroartemisinin - 10- $\alpha$ artesunate, preparation of authentic 10- $\beta$ artesunate, and of other ester and ether derivatives bearing potential aromatic intercalating groups at C-10," European Journal of Organic Chemistry, vol. 2002, no. 1, pp. 113-132, 2002.

[12] D. L. Klayman, "Qinghaosu (artemisinin): an antimalarial drug from China," Science, vol. 228, no. 4703, pp. 1049-1055, 1985.

[13] R. K. Haynes, "From artemisinin to new artemisinin antimalarials: biosynthesis, extraction, old and new derivatives, stereochemistry and medicinal chemistry requirements," Current Topics in Medicinal Chemistry, vol. 6, no. 5, pp. 509537, 2006.

[14] D. J. Creek, W. N. Charman, F. C. K. Chiu et al., "Relationship between antimalarial activity and heme alkylation for spiro- and dispiro-1,2,4-trioxolane antimalarials," Antimicrobial Agents and Chemotherapy, vol. 52, no. 4, pp. 1291-1296, 2008.

[15] C. W. Jefford, "New developments in synthetic peroxidic drugs as artemisinin mimics," Drug Discovery Today, vol. 12, no. 11-12, pp. 487-495, 2007.

[16] A. P. Ramirez, A. M. Thomas, and K. A. Woerpel, "Preparation of bicyclic 1,2,4-trioxanes from $\gamma, \delta$-unsaturated ketones," Organic Letters, vol. 11, no. 3, pp. 507-510, 2009.

[17] D. K. Taylor, T. D. Avery, B. W. Greatrex et al., "Novel endoperoxide antimalarials: synthesis, heme binding, and antimalarial activity," Journal of Medicinal Chemistry, vol. 47, no. 7, pp. 1833-1839, 2004.

[18] C. W. Jefford, J. Velarde, and G. Bernardinelli, "Synthesis of tricyclic arteannuin-like compounds," Tetrahedron Letters, vol. 30, no. 34, pp. 4485-4488, 1989.

[19] G. H. Posner, Chang Ho Oh, L. Gerena, and W. K. Milhous, "Extraordinarily potent antimalarial compounds: new, structurally simple, easily synthesized, tricyclic 1,2,4-trioxanes," Journal of Medicinal Chemistry, vol. 35, no. 13, pp. 24592467, 1992.

[20] S. R. Meshnick, A. Thomas, A. Ranz, C. M. Xu, and H. Z. Pan, "Artemisinin (qinghaosu): the role of intracellular hemin in its mechanism of antimalarial action," Molecular and Biochemical Parasitology, vol. 49, no. 2, pp. 181-189, 1991.

[21] P. L. Olliaro, R. K. Haynes, B. Meunier, and Y. Yuthavong, "Possible modes of action of the artemisinin-type compounds," Trends in Parasitology, vol. 17, no. 3, pp. 122-126, 2001.

[22] P. M. O’Neill, V. E. Barton, and S. A. Ward, “The molecular mechanism of action of artemisinin-the debate continues," Molecules, vol. 15, no. 3, pp. 1705-1721, 2010.

[23] N. Klonis, M. P. Crespo-Ortiz, I. Bottova et al., "Artemisinin activity against Plasmodium falciparum requires hemoglobin uptake and digestion," Proceedings of the National Academy of Sciences of the United States of America, vol. 108, no. 28, pp. 11405-11410, 2011. 
[24] X. Shuhua, S. Binggui, J. Utzinger, J. Chollet, and M. Tanner, "Ultrastructural alterations in adult Schistosoma mansoni caused by artemether," Memorias do Instituto Oswaldo Cruz, vol. 97, no. 5, pp. 717-724, 2002.

[25] A. M. Galal, S. A. Ross, M. A. ElSohly et al., "Deoxyartemisinin derivatives from photooxygenation of anhydrodeoxydihydroartemisinin and their cytotoxic evaluation," Journal of Natural Products, vol. 65, no. 2, pp. 184-188, 2002.

[26] A. C. Beekman, P. K. Wierenga, H. J. Woerdenbag et al., "Artemisinin-derived sesquiterpene lactones as potential antitumour compounds: cytotoxic action against bone marrow and tumour cells," Planta Medica, vol. 64, no. 7, pp. 615$619,1998$.

[27] B. Meunier and A. Robert, "Heme as trigger and target for trioxane-containing antimalarial drugs," Accounts of Chemical Research, vol. 43, no. 11, pp. 1444-1451, 2010.

[28] A. E. Mercer, J. L. Maggs, X. M. Sun et al., "Evidence for the involvement of carbon-centered radicals in the induction of apoptotic cell death by artemisinin compounds," Journal of Biological Chemistry, vol. 282, no. 13, pp. 9372-9382, 2007.

[29] S. Zhang and G. S. Gerhard, "Heme mediates cytotoxicity from artemisinin and serves as a general anti-proliferation target," PLoS ONE, vol. 4, no. 10, Article ID e7472, 2009.

[30] T. G. Berger, D. Dieckmann, T. Efferth et al., "Artesunate in the treatment of metastatic uveal melanoma-first experiences," Oncology Reports, vol. 14, no. 6, pp. 1599-1603, 2005.

[31] A. Hamacher-Brady, H. A. Stein, S. Turschner et al., "Artesunate activates mitochondrial apoptosis in breast cancer cells via iron-catalyzed lysosomal reactive oxygen species production," Journal of Biological Chemistry, vol. 286, no. 8, pp. 6587-6601, 2011.

[32] N. P. Singh and H. C. Lai, "Artemisinin induces apoptosis in human cancer cells," Anticancer Research, vol. 24, no. 4, pp. 2277-2280, 2004.

[33] J. J. Lu, L. H. Meng, U. T. Shankavaram et al., "Dihydroartemisinin accelerates c-MYC oncoprotein degradation and induces apoptosis in c-MYC-overexpressing tumor cells," Biochemical Pharmacology, vol. 80, no. 1, pp. 22-30, 2010.

[34] J. J. Lu, S. M. Chen, X. W. Zhang, J. Ding, and L. H. Meng, "The anti-cancer activity of dihydroartemisinin is associated with induction of iron-dependent endoplasmic reticulum stress in colorectal carcinoma HCT116 cells," Investigational New Drugs, vol. 7, pp. 1-8, 2010.

[35] A. E. Mercer, I. M. Copple, J. L. Maggs, P. M. O'Neill, and B. K. Park, "The role of heme and the mitochondrion in the chemical and molecular mechanisms of mammalian cell death induced by the artemisinin antimalarials," Journal of Biological Chemistry, vol. 283, no. 2, pp. 987-996, 2011.

[36] H. Lai and N. P. Singh, "Selective cancer cell cytotoxicity from exposure to dihydroartemisinin and holotransferrin," Cancer Letters, vol. 91, no. 1, pp. 41-46, 1995.

[37] H. Lai, I. Nakase, E. Lacoste, N. P. Singh, and T. Sasaki, "Artemisinin-transferrin conjugate retards growth of breast tumors in the rat," Anticancer Research, vol. 29, no. 10, pp. 3807-3810, 2009.

[38] I. Nakase, H. Lai, N. P. Singh, and T. Sasaki, "Anticancer properties of artemisinin derivatives and their targeted delivery by transferrin conjugation," International Journal of Pharmaceutics, vol. 354, no. 1-2, pp. 28-33, 2007.

[39] H. Lai, T. Sasaki, and N. P. Singh, "Targeted treatment of cancer with artemisinin and artemisinin-tagged iron-carrying compounds," Expert Opinion on Therapeutic Targets, vol. 9, no. 5, pp. 995-1007, 2005.
[40] L. H. Stockwin, B. Han, S. X. Yu et al., "Artemisinin dimer anticancer activity correlates with heme-catalyzed reactive oxygen species generation and endoplasmic reticulum stress induction," International Journal of Cancer, vol. 125, no. 6, pp. 1266-1275, 2009.

[41] X. J. Huang, Z. Q. Ma, W. P. Zhang, Y. B. Lu, and E. Q. Wei, "Dihydroartemisinin exerts cytotoxic effects and inhibits hypoxia inducible factor- $1 \alpha$ activation in C6 glioma cells," Journal of Pharmacy and Pharmacology, vol. 59, no. 6, pp. 849856, 2007.

[42] J. C. Kwok and D. R. Richardson, "The iron metabolism of neoplastic cells: alterations that facilitate proliferation?" Critical Reviews in Oncology/Hematology, vol. 42, no. 1, pp. 6578, 2002.

[43] T. Efferth, A. Benakis, M. R. Romero et al., "Enhancement of cytotoxicity of artemisinins toward cancer cells by ferrous iron," Free Radical Biology and Medicine, vol. 37, no. 7, pp. 998-1009, 2004.

[44] Q. Xu, Z. -X. Li, H. -Q. Peng et al., "Artesunate inhibits growth and induces apoptosis in human osteosarcoma HOS cell line In vitro and In vivo," Biomedicine and Biotechnology, vol. 12, no. 4, pp. 247-255, 2011.

[45] W. S. May and P. Cuatrecasas, "Transferrin receptor: its biological significance," Journal of Membrane Biology, vol. 88, no. 3, pp. 205-215, 1985.

[46] D. G. Bostwick, E. E. Alexander, R. Singh et al., "Antioxidant enzyme expression and reactive oxygen species damage in prostatic intraepithelial neoplasia and cancer," Cancer, vol. 89, no. 1, pp. 123-134, 2000.

[47] U. N. Das, "A radical approach to cancer," Medical Science Monitor, vol. 8, no. 4, pp. RA79-RA92, 2002.

[48] J. B. Hansen, N. Fisker, M. Westergaard et al., "SPC3042: a proapoptotic survivin inhibitor," Molecular Cancer Therapeutics, vol. 7, no. 9, pp. 2736-2745, 2008.

[49] M. D. P. Crespo, T. D. Avery, E. Hanssen et al., "Artemisinin and a series of novel endoperoxide antimalarials exert early effects on digestive vacuole morphology," Antimicrobial Agents and Chemotherapy, vol. 52, no. 1, pp. 98-109, 2008.

[50] I. D. Ferreira, D. Lopes, A. Martinelli, C. Ferreira, V. E. Do Rosário, and P. Cravo, "In vitro assessment of artesunate, artemether and amodiaquine susceptibility and molecular analysis of putative resistance-associated mutations of Plasmodium falciparum from São Tomé and Príncipe," Tropical Medicine and International Health, vol. 12, no. 3, pp. 353362, 2007.

[51] J. H. Du, H. D. Zhang, Z. J. Ma, and K. M. Ji, "Artesunate induces oncosis-like cell death In vitro and has antitumor activity against pancreatic cancer xenografts In vivo," Cancer Chemotherapy and Pharmacology, vol. 65, no. 5, pp. 895-902, 2010.

[52] M. Michaelis, M. C. Kleinschmidt, S. Barth et al., "Anticancer effects of artesunate in a panel of chemoresistant neuroblastoma cell lines," Biochemical Pharmacology, vol. 79, no. 2, pp. 130-136, 2010.

[53] S. J. Kim, M. S. Kim, J. W. Lee et al., "Dihydroartemisinin enhances radiosensitivity of human glioma cells In vitro," Journal of Cancer Research and Clinical Oncology., vol. 132, no. 2, pp. 129-135, 2006.

[54] Y. Y. Lu, T. S. Chen, X. P. Wang, and L. Li, "Single-cell analysis of dihydroartemisinin-induced apoptosis through reactive oxygen species-mediated caspase- 8 activation and mitochondrial pathway in ASTC-a-1 cells using fluorescence imaging techniques," Journal of Biomedical Optics, vol. 15, no. 4, p. $046028,2010$. 
[55] S. Noori, Z. M. Hassan, M. Taghikhani, B. Rezaei, and Z. Habibi, "Dihydroartemisinin can inhibit calmodulin, calmodulin-dependent phosphodiesterase activity and stimulate cellular immune responses," International Immunopharmacology, vol. 10, no. 2, pp. 213-217, 2010.

[56] D. Mu, W. Chen, B. Yu, C. Zhang, Y. Zhang, and H. Qi, "Calcium and survivin are involved in the induction of apoptosis by dihydroartemisinin in human lung cancer SPC-A1 cells," Methods and Findings in Experimental and Clinical Pharmacology, vol. 29, no. 1, pp. 33-38, 2007.

[57] D. Mu, W. Zhang, D. Chu et al., "The role of calcium, P38 MAPK in dihydroartemisinin-induced apoptosis of lung cancer PC-14 cells," Cancer Chemotherapy and Pharmacology, vol. 61, no. 4, pp. 639-645, 2008.

[58] T. Efferth, "Willmar Schwabe Award 2006: antiplasmodial and antitumor activity of artemisinin from bench to bedside," Planta Medica, vol. 73, no. 4, pp. 299-309, 2007.

[59] C. Riganti, S. Doublier, D. Viarisio et al., "Artemisinin induces doxorubicin resistance in human colon cancer cells via calcium-dependent activation of HIF- $1 \alpha$ and P-glycoprotein overexpression," British Journal of Pharmacology, vol. 156, no. 7, pp. 1054-1066, 2009.

[60] Y. Liu, C. N. Lok, B. C. B. Ko, T. Y. T. Shum, M. K. Wong, and C. M. Che, "Subcellular localization of a fluorescent artemisinin derivative to endoplasmic reticulum," Organic Letters, vol. 12, no. 7, pp. 1420-1423, 2010.

[61] C. Morrissey, B. Gallis, J. W. Solazzi et al., "Effect of artemisinin derivatives on apoptosis and cell cycle in prostate cancer cells," Anti-Cancer Drugs, vol. 21, no. 4, pp. 423-432, 2010.

[62] Y. Y. Lu, T. S. Chen, J. L. Qu, W. L. Pan, L. Sun, and X. B. Wei, "Dihydroartemisinin (DHA) induces caspase-3-dependent apoptosis in human lung adenocarcinoma ASTC-a-1 cells," Journal of Biomedical Science, vol. 16, no. 1, article 16, 2009.

[63] A. M. Gravett, W. M. Liu, S. Krishna et al., "In vitro study of the anti-cancer effects of artemisone alone or in combination with other chemotherapeutic agents," Cancer Chemotherapy and Pharmacology, pp. 569-577, 2010.

[64] E. R. McDonald 3rd. E.R. and W. S. El-Deiry, "Cell cycle control as a basis for cancer drug development (Review)," International Journal of Oncology, vol. 16, no. 5, pp. 871-886, 2000.

[65] B. Vogelstein and K. W. Kinzler, "Cancer genes and the pathways they control," Nature Medicine, vol. 10, no. 8, pp. 789799, 2004.

[66] H. J. Woerdenbag, T. A. Moskal, N. Pras et al., "Cytotoxicity of artemisinin-related endoperoxides to Ehrlich ascites tumor cells," Journal of Natural Products, vol. 56, no. 6, pp. 849856, 1993.

[67] J. Hou, D. Wang, R. Zhang, and H. Wang, "Experimental therapy of hepatoma with artemisinin and Its derivatives: In vitro and In vivo activity, chemosensitization, and mechanisms of action," Clinical Cancer Research, vol. 14, no. 17, pp. 5519-5530, 2008.

[68] L. Yao, H. Xie, Q.-Y. Jin, W.-L. Hu, and L.-J. Chen, "Analyzing anti-cancer action mechanisms of dihydroartemisinin using gene chip," China Journal of Chinese Materia Medica, vol. 33, no. 13, pp. 1583-1586, 2008.

[69] Y. Jiao, C. M. Ge, Q. H. Meng, J. P. Cao, J. Tong, and S. J. Fan, "Dihydroartemisinin is an inhibitor of ovarian cancer cell growth," Acta Pharmacologica Sinica, vol. 28, no. 7, pp. 1045-1056, 2007.
[70] M. Malumbres and M. Barbacid, "To cycle or not to cycle: a critical decision in cancer," Nature Reviews Cancer, vol. 1, no. 3, pp. 222-231, 2001.

[71] D. G. Johnson and C. L. Walker, "Cyclins and cell cycle checkpoints," Annual Review of Pharmacology and Toxicology, vol. 39, pp. 295-312, 1999.

[72] G. L. Firestone and S. N. Sundar, "Anticancer activities of artemisinin and its bioactive derivatives," Expert Reviews in Molecular Medicine, vol. 11, p. e32, 2009.

[73] Y. Ji, Y. C. Zhang, L. B. Pei, L. L. Shi, J. L. Yan, and X. H. Ma, "Anti-tumor effects of dihydroartemisinin on human osteosarcoma," Molecular and Cellular Biochemistry, vol. 351, no. 1-2, pp. 99-108, 2011.

[74] H. Chen, B. Sun, S. Pan, H. Jiang, and X. Sun, "Dihydroartemisinin inhibits growth of pancreatic cancer cells In vitro and In vivo," Anti-Cancer Drugs, vol. 20, no. 2, pp. 131-140, 2009.

[75] W. Aung, C. Sogawa, T. Furukawa, and T. Saga, "Anticancer effect of dihydroartemisinin (DHA) in a pancreatic tumor model evaluated by conventional methods and optical imaging," Anticancer Research, vol. 31, no. 5, pp. 1549-1558, 2011.

[76] S. -J. Wang, B. Sun, Z. -X. Cheng et al., "Dihydroartemisinin inhibits angiogenesis in pancreatic cancer by targeting the NF- $\kappa$ B pathway," Cancer Chemotherapy and Pharmacology. In press.

[77] T. Chen, M. Li, R. Zhang, and H. Wang, "Dihydroartemisinin induces apoptosis and sensitizes human ovarian cancer cells to carboplatin therapy," Journal of Cellular and Molecular Medicine, vol. 13, no. 7, pp. 1358-1370, 2009.

[78] J. Wang, Y. Guo, B. C. Zhang, Z. T. Chen, and J. F. Gao, "Induction of apoptosis and inhibition of cell migration and tube-like formation by dihydroartemisinin in murine lymphatic endothelial cells," Pharmacology, vol. 80, no. 4, pp. 207-218, 2007.

[79] C. M. Cabello, S. D. Lamore, W. B. Bair III et al., "The redox antimalarial dihydroartemisinin targets human metastatic melanoma cells but not primary melanocytes with induction of NOXA-dependent apoptosis," Investigational New Drugs. In press.

[80] R. Handrick, T. Ontikatze, K. D. Bauer et al., "Dihydroartemisinin induces apoptosis by a bak-dependent intrinsic pathway," Molecular Cancer Therapeutics, vol. 9, no. 9, pp. 2497-2510, 2010.

[81] Y. P. Hwang, H. J. Yun, H. G. Kim, E. H. Han, G. W. Lee, and H. G. Jeong, "Suppression of PMA-induced tumor cell invasion by dihydroartemisinin via inhibition of PKC $\alpha /$ Raf/MAPKs and NF- $\kappa$ B/AP-1-dependent mechanisms," Biochemical Pharmacology, vol. 79, no. 12, pp. 17141726, 2010.

[82] H. J. Zhou, W. Q. Wang, G. D. Wu, J. Lee, and A. Li, "Artesunate inhibits angiogenesis and downregulates vascular endothelial growth factor expression in chronic myeloid leukemia K562 cells," Vascular Pharmacology, vol. 47, no. 2-3, pp. 131-138, 2007.

[83] J. Wang, B. Zhang, Y. Guo et al., "Artemisinin inhibits tumor lymphangiogenesis by suppression of vascular endothelial growth factor C," Pharmacology, vol. 82, no. 2, pp. 148-155, 2008.

[84] H. J. Zhou, J. L. Zhang, A. Li, Z. Wang, and X. E. Lou, "Dihydroartemisinin improves the efficiency of chemotherapeutics in lung carcinomas In vivo and inhibits murine Lewis lung carcinoma cell line growth In vitro," Cancer Chemotherapy and Pharmacology, vol. 66, no. 1, pp. 21-29, 2010. 
[85] G. L. Disbrow, A. C. Baege, K. A. Kierpiec et al., "Dihydroartemisinin is cytotoxic to papillomavirus-expressing epithelial cells In vitro and In vivo," Cancer Research, vol. 65, no. 23, pp. 10854-10861, 2005.

[86] W. Lijuan, "Effect of artesunate on human endometrial carcinoma," Journal of Medical Colleges of PLA, vol. 25, no. 3, pp. 143-151, 2010.

[87] M. Youns, T. Efferth, J. Reichling, K. Fellenberg, A. Bauer, and J. D. Hoheisel, "Gene expression profiling identifies novel key players involved in the cytotoxic effect of Artesunate on pancreatic cancer cells," Biochemical Pharmacology, vol. 78, no. 3, pp. 273-283, 2009.

[88] S. A. K. Rasheed, T. Efferth, I. A. Asangani, and H. Allgayer, "First evidence that the antimalarial drug artesunate inhibits invasion and In vivo metastasis in lung cancer by targeting essential extracellular proteases," International Journal of Cancer, vol. 127, no. 6, pp. 1475-1485, 2010.

[89] L. N. Li, H. D. Zhang, S. J. Yuan, D. X. Yang, L. Wang, and Z. $X$. Sun, "Differential sensitivity of colorectal cancer cell lines to artesunate is associated with expression of beta-catenin and E-cadherin," European Journal of Pharmacology, vol. 588, no. 1, pp. 1-8, 2008.

[90] S. Li, F. Xue, Z. Cheng et al., "Effect of artesunate on inhibiting proliferation and inducing apoptosis of SP2/0 myeloma cells through affecting NF $\kappa \mathrm{B}$ p65," International Journal of Hematology, vol. 90, no. 4, pp. 513-521, 2009.

[91] T. Weifeng, S. Feng, L. Xiangji et al., "Artemisinin inhibits In vitro and In vivo invasion and metastasis of human hepatocellular carcinoma cells," Phytomedicine, vol. 18, no. 2-3, pp. 158-162, 2011.

[92] J. Wu, D. Hu, G. Yang et al., "Down-regulation of BMI-1 cooperates with artemisinin on growth inhibition of nasopharyngeal carcinoma cells," Journal of Cellular Biochemistry, vol. 112, no. 7, pp. 1938-1948, 2011.

[93] E. Buommino, A. Baroni, N. Canozo et al., "Artemisinin reduces human melanoma cell migration by down-regulating $\alpha \mathrm{v} \beta 3$ integrin and reducing metalloproteinase 2 production," Investigational New Drugs, vol. 27, no. 5, pp. 412-418, 2008.

[94] S. J. Wang, Y. Gao, H. Chen et al., "Dihydroartemisinin inactivates NF- $\kappa \mathrm{B}$ and potentiates the anti-tumor effect of gemcitabine on pancreatic cancer both In vitro and In vivo," Cancer Letters, vol. 293, no. 1, pp. 99-108, 2010.

[95] A. G. Uren, L. Wong, M. Pakusch et al., "Survivin and the inner centromere protein INCENP show similar cell-cycle localization and gene knockout phenotype," Current Biology, vol. 10, no. 21, pp. 1319-1328, 2000.

[96] J. A. Willoughby, S. N. Sundar, M. Cheung, A. S. Tin, J. Modiano, and G. L. Firestone, "Artemisinin blocks prostate cancer growth and cell cycle progression by disrupting Sp1 interactions with the cyclin-dependent kinase-4 (CDK4) promoter and inhibiting CDK4 gene expression," Journal of Biological Chemistry, vol. 284, no. 4, pp. 2203-2213, 2009.

[97] D. Karnak and L. Xu, "Chemosensitization of prostate cancer by modulating Bcl-2 family proteins," Current Drug Targets, vol. 11, no. 6, pp. 699-707, 2010.

[98] S. Elmore, "Apoptosis: a review of programmed cell death," Toxicologic Pathology, vol. 35, no. 4, pp. 495-516, 2007.

[99] T. Efferth, M. Glaisi, A. Merling, P. H. Krammer, and M. LiWeber, "Artesunate induces ROS-mediated apoptosis in Doxorubicin-resistant T leukemia cells," PLoS ONE, vol. 2, no. 8, article e693, 2007.
[100] Q. He, J. Shi, X. L. Shen et al., "Dihydroartemisinin upregulates death receptor 5 expression and cooperates with TRAIL to induce apoptosis in human prostate cancer cells," Cancer Biology and Therapy, vol. 9, no. 10, pp. 817-823, 2010.

[101] P. S. Steeg, "Tumor metastasis: mechanistic insights and clinical challenges," Nature Medicine, vol. 12, no. 8, pp. 895-904, 2006.

[102] M. J. Duffy, P. M. McGowan, and W. M. Gallagher, "Cancer invasion and metastasis: changing views," Journal of Pathology, vol. 214, no. 3, pp. 283-293, 2008.

[103] W. C. Hung and H. C. Chang, "Indole-3-carbinol inhibits Sp1-induced matrix metalloproteinase- 2 expression to attenuate migration and invasion of breast cancer cells," Journal of Agricultural and Food Chemistry, vol. 57, no. 1, pp. 76-82, 2009.

[104] E. Hur, H. H. Kim, S. M. Choi et al., "Reduction of hypoxiainduced transcription through the repression of hypoxia-inducible factor- $1 \alpha /$ aryl hydrocarbon receptor nuclear translocator DNA binding by the $90-\mathrm{kDa}$ heat-shock protein inhibitor radicicol," Molecular Pharmacology, vol. 62, no. 5, pp. 975-982, 2002.

[105] L. Anfosso, T. Efferth, A. Albini, and U. Pfeffer, "Microarray expression profiles of angiogenesis-related genes predict tumor cell response to artemisinins," Pharmacogenomics Journal, vol. 6, no. 4, pp. 269-278, 2006.

[106] H. H. Chen, H. J. Zhou, W. Q. Wang, and G. D. Wu, "Antimalarial dihydroartemisinin also inhibits angiogenesis," Cancer Chemotherapy and Pharmacology, vol. 53, no. 5, pp. 423432, 2004.

[107] X. J. Huang, C. T. Li, W. P. Zhang, Y. B. Lu, S. H. Fang, and E. Q. Wei, "Dihydroartemisinin potentiates the cytotoxic effect of temozolomide in rat C6 glioma cells," Pharmacology, vol. 82, no. 1, pp. 1-9, 2008.

[108] R. O'Connor, “The pharmacology of cancer resistance," Anticancer Research, vol. 27, no. 3 A, pp. 1267-1272, 2007.

[109] W. Chaijaroenkul, V. Viyanant, W. Mahavorasirikul, and K. Na-Bangchang, "Cytotoxic activity of artemisinin derivatives against cholangiocarcinoma (CL-6) and hepatocarcinoma (Hep-G2) cell lines," Asian Pacific Journal of Cancer Prevention, vol. 12, no. 1, pp. 55-59, 2011.

[110] N. P. Singh and H. C. Lai, "Synergistic cytotoxicity of artemisinin and sodium butyrate on human cancer cells," Anticancer Research, vol. 25, no. 6 B, pp. 4325-4331, 2005.

[111] W. M. Liu, A. M. Gravett, and A. G. Dalgleish, "The antimalarial agent artesunate possesses anticancer properties that can be enhanced by combination strategies," International Journal of Cancer, vol. 128, no. 6, pp. 1471-1480, 2011.

[112] Y. Ohgami, C. A. Elstad, E. Chung, D. Y. Shirachi, R. M. Quock, and H. C. Lai, "Effect of hyperbaric oxygen on the anticancer effect of artemisinin on molt-4 human leukemia cells," Anticancer Research, vol. 30, no. 11, pp. 4467-4470, 2010.

[113] B. Witkowski, J. Lelièvre, M. J.L. Barragán et al., "Increased tolerance to artemisinin in Plasmodium falciparum is mediated by a quiescence mechanism," Antimicrobial Agents and Chemotherapy, vol. 54, no. 5, pp. 1872-1877, 2010.

[114] J. F. Head, F. Wang, and R. L. Elliott, "Antineoplastic drugs that interfere with iron metabolism in cancer cells," Advances in Enzyme Regulation, vol. 37, pp. 147-169, 1997.

[115] S. Sertel, T. Eichhorn, S. Sieber et al., "Factors determining sensitivity or resistance of tumor cell lines towards artesunate," Chemico-Biological Interactions, vol. 185, no. 1, pp. 42$52,2010$. 
[116] B. Bachmeier, I. Fichtner, P. H. Killian, E. Kronski, U. Pfeffer, and T. Efferth, "Development of resistance towards artesunate in MDA-MB-231 human breast cancer cells," PLoS ONE, vol. 6, no. 5, article e20550, 2011.

[117] W. McLean and S. A. Ward, "In vitro neurotoxicity of artemisinin derivatives," Médecine Tropicale, vol. 58, no. 3, pp. 2831, 1998.

[118] G. Schmuck, E. Roehrdanz, R. K. Haynes, and R. Kahl, "Neurotoxic mode of action of artemisinin," Antimicrobial Agents and Chemotherapy, vol. 46, no. 3, pp. 821-827, 2002.

[119] E. Kissinger, T. T. Hien, N. T. Hung et al., "Clinical and neurophysiological study of the effects of multiple doses of artemisinin on brain-stem function in vietnamese patients," American Journal of Tropical Medicine and Hygiene, vol. 63, no. 1-2, pp. 48-55, 2000.

[120] Y. Si, Q. Li, L. Xie et al., "Neurotoxicity and toxicokinetics of artelinic acid following repeated oral administration in rats," International Journal of Toxicology, vol. 26, no. 5, pp. 401-410, 2007.

[121] T. Efferth and B. Kaina, "Toxicity of the antimalarial artemisinin and its dervatives," Critical Reviews in Toxicology, vol. 40, no. 5, pp. 405-421, 2010.

[122] N. P. Singh and K. B. Verma, "Case report of a laryngeal squamous cell carcinoma treated with artesunate," Archive of Oncology, vol. 10, no. 4, pp. 279-280, 2002.

[123] N. P. Singh and V. K. Panwar, "Case report of a pituitary macroadenoma treated with artemether," Integrative Cancer Therapies, vol. 5, no. 4, pp. 391-394, 2006.

[124] L. A. Panossian, N. I. Garga, and D. Pelletier, "Toxic brainstem encephalopathy after artemisinin treatment for breast cancer," Annals of Neurology, vol. 58, no. 5, pp. 812-813, 2005.

[125] S. Campos, P. de la Cerda, and A. Rivera, "Fatal artesunate toxicity in a child," Journal of Pediatric Infectious Diseases, vol. 3, no. 1, pp. 69-75, 2008.

[126] Z. Y. Zhang, S. Q. Yu, L. Y. Miao et al., "Artesunate combined with vinorelbine plus cisplatin in treatment of advanced nonsmall cell lung cancer: a randomized controlled trial," Journal of Chinese Integrative Medicine, vol. 6, no. 2, pp. 134-138, 2008.

[127] S. Lee, "Synthesis of 10B-Substituited triazolyl artemisinins and their growth inhibitory activity against various cancer cells," Bulletin of the Korean Chemical Society, vol. 32, no. 2, pp. 737-740, 2011.

[128] F. S. Feng, E. M. Guantai, M. J. Nell, C. E. J. van Rensburg, H. Hoppe, and K. Chibale, "Antiplasmodial and antitumor activity of dDHA analogs derived via the aza-Michael addition reaction," Bioorganic and Medicinal Chemistry Letters, vol. 21, no. 10, pp. 2882-2886, 2000.

[129] C. H. Lee, H. Hong, J. Shin et al., "NMR studies on novel antitumor drug candidates, deoxoartemisinin and carboxypropyldeoxoartemisinin," Biochemical and Biophysical Research Communications, vol. 274, no. 2, pp. 359-369, 2000.

[130] A. A. Alagbala, A. J. McRiner, K. Borstnik et al., "Biological mechanisms of action of novel C-10 non-acetal trioxane dimers in prostate cancer cell lines," Journal of Medicinal Chemistry, vol. 49, no. 26, pp. 7836-7842, 2006.

[131] C. Horwedel, S. B. Tsogoeva, S. Wei, and T. Efferth, "Cytotoxicity of artesunic acid homo- and heterodimer molecules toward sensitive and multidrug-resistant CCRF-CEM leukemia cells," Journal of Medicinal Chemistry, vol. 53, no. 13, pp. 4842-4848, 2010.
[132] J. P. Jeyadevan, P. G. Bray, J. Chadwick et al., "Antimalarial and Antitumor Evaluation of Novel C-10 Non-Acetal Dimers of 10 $\beta$-(2-Hydroxyethyl)deoxoartemisinin," Journal of Medicinal Chemistry, vol. 47, no. 5, pp. 1290-1298, 2004.

[133] M. Jung, S. Lee, J. Ham, K. Lee, H. Kim, and S. Kie Kim, "Antitumor activity of novel deoxoartemisinin monomers, dimers, and trimer," Journal of Medicinal Chemistry, vol. 46, no. 6, pp. 987-994, 2003.

[134] D. Opsenica, G. Pocsfalvi, Z. Juranic et al., "Cholic acid derivatives as 1,2,4,5-tetraoxane carriers: structure and antimalarial and antiproliferative activity," Journal of Medicinal Chemistry, vol. 43, no. 17, pp. 3274-3282, 2000.

[135] S. Soomro, T. Langenberg, A. Mahringer et al., "Design of novel artemisinin-like derivatives with cytotoxic and antiangiogenic properties," Journal of Cellular and Molecular Medicine, vol. 15, no. 5, pp. 1122-1135, 2011.

[136] P. J. de Vries and T. K. Dien, "Clinical pharmacology and therapeutic potential of artemisinin and its derivatives in the treatment of malaria," Drugs, vol. 52, no. 6, pp. 818-836, 1996.

[137] S. Krishna, A. C. Uhlemann, and R. K. Haynes, "Artemisinins: mechanisms of action and potential for resistance," Drug Resistance Updates, vol. 7, no. 4-5, pp. 233-244, 2004.

[138] S. A. Charman, S. Arbe-Barnes, I. C. Bathurst et al., "Synthetic ozonide drug candidate OZ439 offers new hope for a single-dose cure of uncomplicated malaria," Proceedings of the National Academy of Sciences of the United States of America, vol. 108, no. 11, pp. 4400-4405, 2011.

[139] S. -H. Xiao, J. Keiser, J. Chollet et al., "In vitro and In vivo activities of synthetic trioxolanes against major human schistosome species," Antimicrobial Agents and Chemotherapy, vol. 51, no. 4, pp. 1440-1445, 2007.

[140] I. Opsenica, D. Opsenica, K. S. Smith, W. K. Milhous, and B. A. Šolaja, "Chemical stability of the peroxide bond enables diversified synthesis of potent tetraoxane antimalarials," Journal of Medicinal Chemistry, vol. 51, no. 7, pp. 2261-2266, 2008.

[141] N. Terzić, D. Opsenica, D. Milić et al., "Deoxycholic acidderived tetraoxane antimalarials and antiproliferatives," Journal of Medicinal Chemistry, vol. 50, no. 21, pp. 5118-5127, 2007.

[142] World Health Organization, Guidelines for the Treatment of Malaria, WHO press, Geneva, Switzerland, 2006.

[143] A. R. Yuen, G. Zou, A. T. Turrisi et al., "Reproductive functions in female patients treated with adjuvant and neoadjuvant chemotherapy for localized osteosarcoma of the extremity," Cancer, vol. 89, no. 9, pp. 1961-1965, 2000.

[144] Z. P. Wu, C. W. Gao, Y. G. Wu et al., "Inhibitive effect of artemether on tumor growth and angiogenesis in the rat C6 orthotopic brain gliomas model," Integrative Cancer Therapies, vol. 8, no. 1, pp. 88-92, 2009.

[145] F. Cavallo, C. de Giovanni, P. Nanni, G. Forni, and P. -L. Lollini, "2011: the immune hallmarks of cancer," Cancer Immunology, Immunotherapy, vol. 60, no. 3, pp. 319-326, 2011. 

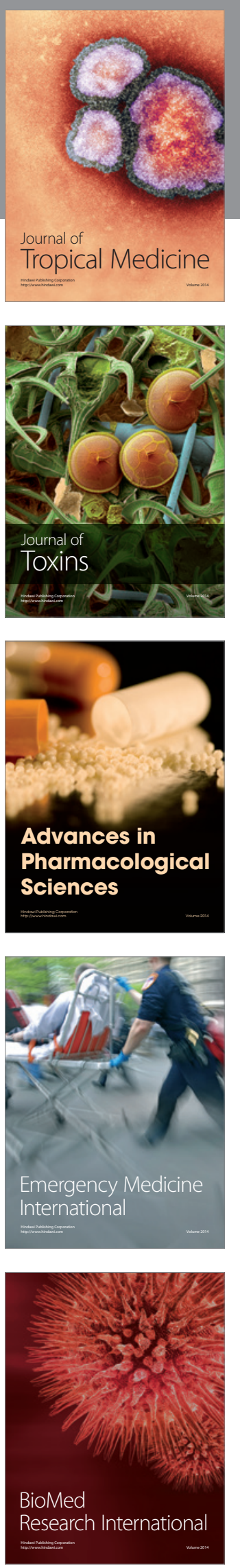
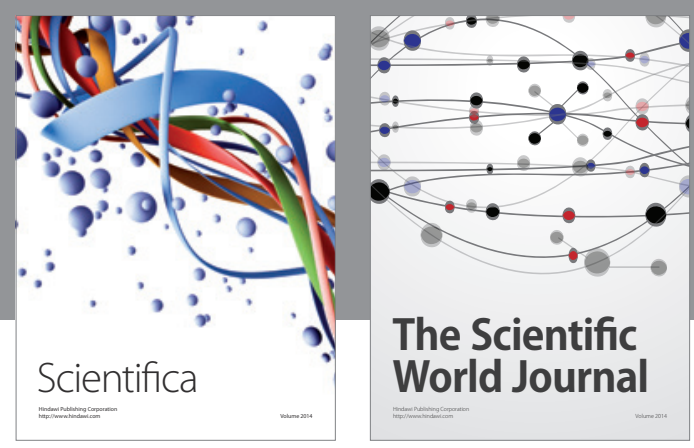

The Scientific World Journal
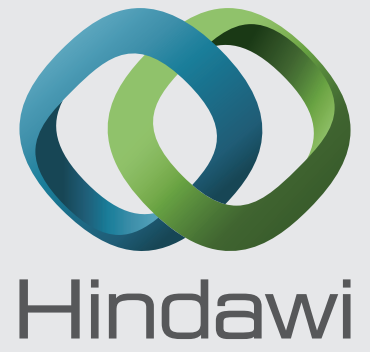

Submit your manuscripts at

http://www.hindawi.com
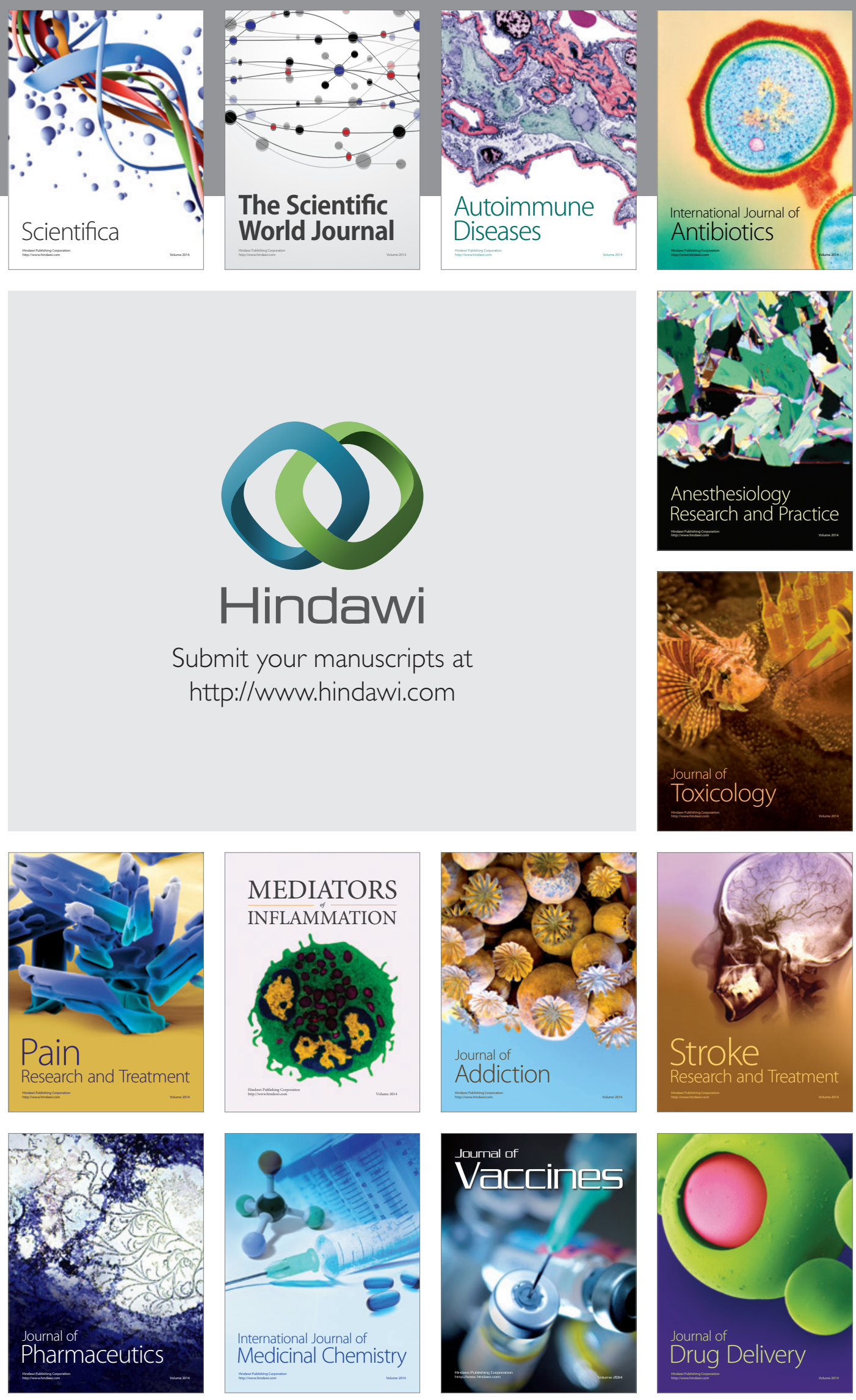